\title{
r.m. \\ Mitophagy: Molecular Mechanisms, New Concepts on Parkin Activation and the Emerging Role of AMPK/ULK1 Axis
}

\author{
Roberto Iorio*(D), Giuseppe Celenza and Sabrina Petricca (D) \\ Department of Biotechnological and Applied Clinical Sciences, University of L'Aquila, Via Vetoio, \\ 67100 L'Aquila, Italy; giuseppe.celenza@univaq.it (G.C.); sabrina.petricca@univaq.it (S.P.) \\ * Correspondence: roberto.iorio@univaq.it; Tel./Fax: +39-0862-433443
}

check for

updates

Citation: Iorio, R.; Celenza, G.; Petricca, S. Mitophagy: Molecular Mechanisms, New Concepts on Parkin Activation and the Emerging Role of AMPK/ULK1 Axis. Cells 2022, 11, 30. https://doi.org/ $10.3390 /$ cells11010030

Academic Editors: Nadine

Camougrand and Ingrid

Bhtia-Kissova

Received: 25 November 2021

Accepted: 22 December 2021

Published: 23 December 2021

Publisher's Note: MDPI stays neutral with regard to jurisdictional claims in published maps and institutional affiliations.

Copyright: (c) 2021 by the authors. Licensee MDPI, Basel, Switzerland. This article is an open access article distributed under the terms and conditions of the Creative Commons Attribution (CC BY) license (https:/ / creativecommons.org/licenses/by/ $4.0 /)$.

\begin{abstract}
Mitochondria are multifunctional subcellular organelles essential for cellular energy homeostasis and apoptotic cell death. It is, therefore, crucial to maintain mitochondrial fitness. Mitophagy, the selective removal of dysfunctional mitochondria by autophagy, is critical for regulating mitochondrial quality control in many physiological processes, including cell development and differentiation. On the other hand, both impaired and excessive mitophagy are involved in the pathogenesis of different ageing-associated diseases such as neurodegeneration, cancer, myocardial injury, liver disease, sarcopenia and diabetes. The best-characterized mitophagy pathway is the PTEN-induced putative kinase 1 (PINK1)/Parkin-dependent pathway. However, other Parkin-independent pathways are also reported to mediate the tethering of mitochondria to the autophagy apparatuses, directly activating mitophagy (mitophagy receptors and other E3 ligases). In addition, the existence of molecular mechanisms other than PINK1-mediated phosphorylation for Parkin activation was proposed. The adenosine $5^{\prime}$-monophosphate (AMP)-activated protein kinase (AMPK) is emerging as a key player in mitochondrial metabolism and mitophagy. Beyond its involvement in mitochondrial fission and autophagosomal engulfment, its interplay with the PINK1-Parkin pathway is also reported. Here, we review the recent advances in elucidating the canonical molecular mechanisms and signaling pathways that regulate mitophagy, focusing on the early role and spatial specificity of the AMPK/ULK1 axis.
\end{abstract}

Keywords: mitophagy; mitochondria; ubiquitin; PINK1-Parkin pathway; Parkin activation; mitophagy receptors; E3 ligases; AMPK; ULK1

\section{Introduction}

Mitochondria are dynamic and multifunctional subcellular compartments forming a sophisticated, interconnected reticulum [1]. They play crucial roles in a range of fundamental processes, including ATP production, heme and steroid hormones biosynthesis, $\mathrm{Ca}^{2+}$ metabolism and signaling, iron homeostasis, fatty acid $B$-oxidation, the regulation of heterotypic inter-organelle contacts, in particular with the endoplasmic reticulum (ER), and cell death [2-6]. Mitochondrial quality and function must be closely controlled to ensure metabolic substrate availability and to forestall the generation of reactive oxygen species (ROS) and oxidizing agents. Moreover, mitochondria contain 1000 proteins mainly located in the matrix [7], and the maintenance of proteostasis is ensured by a set of mitochondrial heat shock proteins (HSP), chaperonins, and proteases. In response to particular stressors (including hypoxia, cytokine stimulation, mitochondrial membrane potential alterations, and calcium influx) mitochondria may generate excessive levels of ROS [8,9]. In order to cope with homeostatic insults, cells have evolved multiple interdependent quality-control mechanisms at molecular, organellar and cellular levels that aim to maintain or restore functions $[10,11]$. The pathways regulating mitochondrial turnover and homeostasis, collectively referred to as mitochondrial quality control (MQC), include DNA repair mechanisms, ROS scavenging, chaperones and proteolytic enzymes, the ubiquitin-proteasome system (UPS), and the mitochondria-specific, unfolded protein response (UPR $\left.{ }^{\mathrm{mt}}\right)$. Mitochondrial 
fusion and fission dynamics, as well as mitochondrial biogenesis and degradation, are also crucial for organelle quality control and maintaining mitochondrial networks [12]. Under stress conditions, mitochondrial fusion and fission events promote content mixing between the compartments that need to be repaired (fusion) and the segregation of damaged organelles (asymmetrical fission) [13-15]. Upon alteration in proteostasis, the $\mathrm{UPR}^{\mathrm{mt}}$ is quickly activated to reduce the buildup of misfolded proteins in the compartment through the transcriptional induction of mitochondrial chaperones and proteases. In particular, $\mathrm{UPR}^{\mathrm{mt}}$ activation in mammals (including humans) enables the nuclear translocation of activating transcription factor 5 (ATF5), resulting in the expression of its downstream effector genes such as HSP22, HSP60, HSP70, C/EBP homologous protein (CHOP), mtDnaJ, the matrix proteases lon protease homolog (LonP1), and ATP-dependent Clp protease proteolytic subunit (ClpP) [16-18]. Several axes of the mammalian $\mathrm{UPR}^{\mathrm{mt}}$ were reported and their association with mitophagy was reported [19-21].

Mitophagy is a highly regulated multistep process in charge of the selective degradation of damaged/dysfunctional mitochondria by autophagy [22] and shares common aspects with other types of selective autophagy (including aggrephagy, ER-phagy, pexophagy, and xenophagy) [23-25]. This is vital for maintaining mitochondrial homeostasis and contributes, with other adaptive responses, to improving mitochondrial quality [20]. Therefore, it acts together with other pathways involved in the mitochondrial turnover, such as mitochondria-derived vesicles (MDVs), piecemeal mitophagy, and outer-mitochondrial, membrane-associated degradation (OMMAD) [20,26].

Basal, programmed, and stress-induced mitophagy, as well as transmitophagy are a few examples of how the term "mitophagy" can be interpreted differently according to the physiological and pathological context [22]. Basal mitophagy, the selective removal of damaged/aged mitochondria under steady-state conditions, was recently demonstrated by in vivo evidence [27-29]. In mouse tissues, it would operate as a housekeeping process, independently of exogenous triggers, to ensure mitochondrial homeostasis [30]. However, its levels change according to the specific tissue taken into consideration and between different cell types of the same tissue. Therefore, based on the energy demand, the basal levels of mitophagy are experienced at low (e.g., thymus) and high rates (e.g., heart and kidney) [27,31].

Programmed mitophagy plays a crucial role in physiological contexts which require the activation of the planned clearance of mitochondria as an element of their developmental programs, including tissue differentiation and protection processes [32,33]. In this regard, mitochondrial degradation was implicated in erythrocyte maturation through NIP3-like protein X (NIX/BNIP3L) activity and platelet activation [34,35]. In addition, the mitophagy-dependent selective clearance of paternal mitochondrial DNA (mtDNA) ensures the inheritance of the maternal mtDNA, following fertilization [36]. Programmed mitophagy occurs during cardiomyocytes and myoblasts maturation, macrophage polarization and retinal ganglion cell (RGC) differentiation, regulating the rewiring of metabolic pathways and the rate of mitochondrial bulk renewal [22].

Stress-induced mitophagy evolved to support the regulation of cell metabolism to external insults. It can be upregulated in response to different types of stresses, such as starvation, exercise, and ischemia [37-39]. It is essential in highly specialized cells primarily dependent on oxidative metabolism for aerobic respiration, such as skeletal muscle cells, neurons, adipocytes, cardiomyocytes, and hepatocytes [40,41]. Importantly, hypoxia was also described as driving mitophagy activation in these cells. The mitochondrial mass reduction would allow adaptive cellular responses to anaerobic conditions [42].

Although mitophagy was considered as a cell-autonomous function, transcellular mitochondrial degradation processes (transmitophagy) may also occur $[43,44]$. The presence of transmitophagy in the basal ganglia and its involvement in integrated neuron-astrocyte interplay are becoming increasingly clear [45].

Over the past decade, our knowledge of the molecular mechanisms regulating mitophagy has significantly advanced, and the involvement of multiple and redundant path- 
ways is becoming increasingly evident. The best-characterized mechanism of mitophagy induction is represented by the PTEN-induced putative kinase 1 (PINK1)/Parkin-dependent pathway [46-48], given the relevance of these factors in autosomal recessive PD [49,50]. Although relevant in mitochondria removal in vitro as a result of specific damage, such as membrane depolarization, this pathway would seem unnecessary for governing basal mitophagy (in mice) in vivo, as well as other forms of selective autophagy [29,30]. In addition, in mice and Drosophila melanogaster deficient for either PINK1 or Parkin, the clearance of dysfunctional mitochondria still occurs [29,51,52]. Therefore, the Parkinindependent pathways ("mitophagy receptors" and "new ubiquitin E3 ligases") were also reported to mediate the tethering of mitochondria to the autophagy apparatuses, directly activating mitophagy and operating to compensate for, or be in parallel to, PINK1-Parkin axis $[22,40,53,54]$. In this sense, signaling molecules (e.g., FUNDC1, BNIP3, BNIP3L/NIX, BCL2-L-13 and FKBP8) or lipids (e.g., cardiolipin) act as mitophagy receptors in responding to the environment and developmental stimuli.

On the other hand, impaired and excessive mitophagy are implicated in the pathogenesis of various ageing-associated diseases, including cancer, myocardial injury, diabetes, liver disease, sarcopenia, and neurological disorders such as Alzheimer's and Parkinson's diseases (AD and $\mathrm{PD}$ ) $[55,56]$. Therefore, promoting mitophagy by pharmacological strategies may be a therapeutic target for diseases associated with mitochondrial dysfunction.

The adenosine5'-monophosphate (AMP)-activated protein kinase (AMPK) (a highly conserved Ser/Thr kinase) is described as a master sensor of cell stress and is emerging as a crucial regulatory factor of mitochondrial metabolism and mitophagy [57]. Indeed, its implication in mitochondrial fission and autophagosomal engulfment, as well as its possible interplay with PINK1-Parkin signaling, was reported. In the present review, we examine recent advances in elucidating the molecular mechanisms that regulate mitochondrial removal and summarize our current knowledge on the signaling pathways governing mitophagy. Although the contributions of mitophagy in normal physiology and human disease are well known, these are beyond the scope of this review. In this regard, several reviews are available that illustrate the role of mitophagy in liver, cardiovascular, immune, inflammatory, and metabolic diseases and cancer [58-62]. Considering the direct connection between AMPK and mitochondrial biology, we also highlight recent advances in the role of the AMPK/ULK1 axis in regulating mitophagy, as well as its possible interplay with PINK1-Parkin signaling.

\section{Regulation of Mitophagy}

\subsection{Chemical and Natural Mitophagy Triggers}

In cultured cell lines, it is experimentally advantageous to use chemical reagents to trigger PINK1-Parkin-mediated mitophagy. In this regard, different compounds were described. An in vitro pharmacological manipulation allowed the dissection of molecular mechanisms underlying selective autophagy, where the acute loss in mitochondrial membrane potential $\left(\Delta \Psi_{\mathrm{m}}\right)$ and the following stabilization of PINK1 could trigger the clearance of damaged mitochondria. Therefore, many protonophores (e.g., (carbonyl cyanide mchlorophenyl hydrazone) CCCP/(carbonylcyanide-p-trifluoromethoxyphenylhydrazone) FCCP) and/or inhibitors of the respiratory chain (e.g., antimycin A/oligomicin) are widely used in biological research to promote mitochondrial depolarization and induce mitophagy via PINK1-Parkin pathway [63]. However, it is important to note that both CCCP and FCCP have some limitations as they exhibit cytotoxicity and are incorporated not only into the IMM (inner mitochondrial membrane), but also in the lysosome membrane, resulting in cytoplasmic acidification [63]. Therefore, new mitophagic inducers working independently of $\Delta \Psi_{\mathrm{m}}$ dissipation and/or Parkin activation were identified. In addition, given the implication of mitophagy in MQC and in a wide variety of ageing-associated diseases, pharmacological approaches that aim to regulate mitophagy are currently receiving significant attention. In this regard, many synthetic chemical compounds (e.g., novel mitochondrial uncoupling agents, oxidative stress inducers, iron chelators, $\mathrm{NAD}^{+}$ 
precursors, and deubiquitinating enzymes and p53 inhibitors) and naturally occurring substances (e.g., spermidine, resveratrol A, urolithin A, and antibiotics) were shown to induce strong mitophagic responses $[64,65]$.

\subsection{PINK1-Parkin Axis}

The best-known mitochondrial stress signaling pathway is the PINK1-Parkin-driven mitophagy, which mediates the specific ubiquitination and subsequent removal of dysfunctional/damaged mitochondria by recruiting autophagic machinery $[46,66]$. The Ser/Thr PINK1 (encoded by PARK6) and the cytosolic Parkin RING (Really Interesting New Gene)/HECT (Homologous to E6-AP Carboxyl Terminus) hybrid ligase (encoded by PARK2) are the critical factors of these molecular mechanisms. They are both mutated in autosomal-recessive PD, suggesting a causative role of impaired PINK1/Parkin-mediated mitophagy in the etiology of the disease [50,67]. Generally, the PINK1-Parkin pathway implicates the stabilization of PINK1 on the outer mitochondrial membrane (OMM), followed by the recruitment and activation of Parkin $[47,68]$. In turn, activated Parkin promotes the ubiquitination of a group of OMM proteins as well as the recruitment of autophagy adaptors, including OPTN (optineurin) and NDP52 (nuclear dot protein 52kDa) to damaged mitochondria [69-72], resulting in the constitution of LC3-associated phagophores, which leads mitochondria to lysosomal degradation.

\subsection{Structure and Activation of Parkin}

Parkin belongs to the RBR (RING-between-RING) E3 ubiquitin family and adopts HECT mechanisms for substrate ubiquitination [73]. It contains a Ubl (N-terminal ubiquitinlike) domain followed by a flexible linker (a series of 60 amino acids), and four zinc-binding RING domains, namely RING0, RING1 (the E2-binding site), IBR (in-between-RING), and RING2 [74-76]. The REP (Repressor Element of Parkin), a short $\alpha$-helix, is localized between the IBR and RING2 domains. All of these domains are conserved across the metazoans. Parkin acts like an RBR/HETC-type E3 ligase by promoting the ubiquitin transfer from an E2 ubiquitin-conjugating enzyme, $\mathrm{UbcH} 7, \mathrm{UbcH} 8$, and Ubc13/Uev1a, onto the catalytic center Cys431 in the RING2 domain, through the formation of an unstable thioester intermediate (transthiolation). Subsequently, ubiquitin is transferred from Parkin to an amino group of a substrate protein (acyl transfer step) via the lysine residue [77,78].

Under steady-state conditions, Parkin adopts an auto-inhibited conformation in which the RING0 domain partially masks Cys431, and both the Ubl domain and REP block the E2-binding site on RING1. Accordingly, the cytosolic ligase is greatly inactivated.

It is now clear that PINK1-mediated phosphorylation on Ser65 residues of both ubiquitin (mono-Ub or multiple-attached $\mathrm{Ubs}$ in a chain at the mitochondrial surface), and the Ubl domain promotes the recruitment of latent Parkin onto the mitochondria, as well as its conversion from an autoinhibited enzyme to fully activated E3 ubiquitin ligase [79,80]. Therefore, PINK1 plays a role as ubiquitin kinase. A recent review goes into depth on the structural findings regulating Parkin activity [81]. PINK1 acts as a mitochondrial damage sensor, and when its import is arrested (under bioenergetics stress, loss in $\Delta \Psi_{\mathrm{m}}$ ), it accumulates on the OMM of dysfunctional mitochondria and phosphorylates $\mathrm{Ub}$ molecules (pUb). The interaction between pUb and RING1 (at a site consisting of His302 and Arg305) of Parkin leads to the disengagement of the Ubl domain from the core structure, resulting in the conformational rearrangements, which in part liberate Parkin from the inhibitory interactions and promote its accumulation at the surface of mitochondria [76,82-89]. Therefore, the $\mathrm{pUb}$ acts as a receptor for Parkin recruitment [90], and the phosphoserine binding on RING1 govern Parkin localization. Subsequently, the Ubl domain of the partially activated configuration of Parkin is recognized and phosphorylated by PINK1 at Ser65. This promotes the interaction between pUbl and RING0 (in a pocket composed of the residues Lys161, Arg163, and Lys211) with the subsequent release of RING2 from RING0-mediated repression, and REP $[79,80]$. As a result, the opening of both E2-binding and catalytic sites enable Parkin to receive $\mathrm{Ub}$ from $\mathrm{Ub}$-E2 with the subsequent ubiquitination of Lys residues 
in target OMM proteins. Parkin regulates the assembly of typical (at Lys48 and Lys63) and atypical ubiquitin chains (at Lys6 and Lys11) to the protein substrates involved in different aspects of mitochondrial functioning [85,91,92]. A large number of proteins undergo Parkinmediated ubiquitination, including Mfn1/2, Miro1, subunits of the TIM/TOM complex and proteasomes, VDAC1/2/3 (voltage-dependent anion channel-1/2/3), metabolic proteins, HK1 (hexokinase-1), and factors of autophagy [93-96]. In total, it was indicated that more than 2000 proteins could be substrates of Parkin [94].

\subsection{The Feed-Forward Mechanism of Parkin Activation}

The addition of new $\mathrm{Ub}$ onto the OMM generates a virtuous circle since the presence of more substrates for PINK1 further increases the content of poly-phosphorylated Ub, leading to the extra activation and recruitment of Parkin to mitochondria. This results in a self-amplifying, feed-forward loop that, at the end, directs mitochondria along the mitophagy pathway. This model elucidates the low substrate selectivity of Parkin, which would be advantageous for advancing the positive feedback cycle, as opposed to its good spatial specificity for impaired mitochondria and the observation that Parkin activity is necessary for its recruitment [85,97-100]. Under basal conditions, it was suggested that other mitochondrial E3 ligases constitutively ubiquitylate mitochondrial substrates (e.g., MITOL/March5, localized at the TOM complex). Following mitochondrial depolarization, the MITOL-mediated ubiquitination would contribute to the early step in mitophagy, introducing the "initial $\mathrm{Ub}^{\prime}$ " required for Parkin recruitment and activation and the subsequent generation of the positive feedback cycle [101].

\subsection{Molecular Links between PINK1/Parkin-Mediated Mitophagy and Mitochondrial Dynamics}

The extensive catalytic activity of the PINK1-Parkin axis suggests the involvement of this pathway in several cellular processes. Therefore, the functional interplay between mitochondrial dynamics and trafficking, and PINK/Parkin system in ensuring the clearance of impaired mitochondria was reported. Indeed, Mfn2 and Miro (a mitochondrial motor/adaptor complex constituent) are targeted by PINK1 and Parkin [102,103]. In mammals, Mfn2 regulates mitochondrial fusion dynamics and ER-mitochondrial tethering [104]. When phosphorylated by PINK1 (at Ser378), Mfn2 adopts a fusion-nonpermissive conformation [105]. Moreover, the PINK1-mediated phosphorylation of Mfn2 on Ser442 and Thr111 enables Parkin-Mfn2 binding, presumably determining the initial recruitment of Parkin to mitochondria, the inhibition of Mfn2-regulated fusion and, ultimately, the activation of the mitophagic mitochondrial clearance [103,106].

The Parkin-mediated ubiquitination of Mfn1/2 leads to its proteasomal degradation by a p97-dependent extraction mechanism [107-110]. Thus, Mfn2 degradation leads to the interdiction of fusion and the induction of fission events as well as to the separation of mitochondria-ER contact sites [110]. The Mfn2 localization in the mitochondria-ER contacts and the detection of PINK1 in MAM (mitochondria-associated membrane) also suggest a PINK1/pUb-mediated Parkin recruitment at the mitochondria-ER sites [111]. Different from the autophagy pathway, mitophagy may exhibit an antagonistic and reciprocal relationship with mitochondria-ER contacts as their reduction is functional to the Parkinmediated ubiquitination of substrates, its recruitment to the OMM and mitochondrial turnover [111].

Other studies indicate that Miro is phosphorylated by PINK1 at multiple amino acid residues, including Ser156. This promotes Miro ubiquitination by Parkin and its subsequent proteasomal degradation [102,112-114]. In this way, Miro degradation and Mfn2 inhibition block mitochondrial motility and fusion, respectively, thus favoring mitochondrial clearance by autophagosome.

\subsection{Deubiquitinating Enzymes and PTEN-L as Regulators of Mitophagy}

The ubiquitination process is reversible and balanced by the activities of deubiquitinating enzymes (DUBs), which modulate protein turnover by removing $\mathrm{Ub}$ from ubiquitinated 
substrates. Many DUBs, such as USP15 (Ub-specific cysteine protease 15), USP30, USP33 and USP35 regulate mitochondrial homeostasis and antagonize PINK1-Parkin-driven mitophagy [92,115-118]. In this regard, a mechanism of action of USP30-mediated K6linkage-specific deubiquitination was suggested [119,120]. USP30 is localized in the OMM, and it is physically associated with TOM complex components [121]. It also regulates the TOM-mitochondrial import by a sort of "tug of war" with MITOL. Therefore, USP30induced low levels of ubiquitination, charged to the specific site of PINK1 stabilization, and may dampen the initial triggering responsible for the PINK/Parkin-mediated amplification process of ubiquitination [122,123]. On the contrary, USP8 acts as a positive regulator of Parkin-driven mitophagy, since the specific removal of K6-linked Ub conjugates from Parkin stimulates its turnover and speeds up the mitophagy process [124]. Although USP30 is traditionally believed to be a negative regulator of Parkin-mediated ubiquitination, its ablation in USP30 knockout cells did not affect the ubiquitination of Parkin substrates $[121,125]$. The picture of the complexity of the deubiquitination reactions is enriched by further elements, since the PINK1-mediated phosphorylation of Ub alters $\mathrm{Ub}$ structure and compromises the enzymatic activities of USP8, USP15, and USP30 [126]. USP35 detaches from depolarized mitochondria and impairs mitophagy with a mechanism independent of Parkin recruitment [127]. On the contrary, upon mitochondrial depolarization USP15 is recruited on the OMM and removes K48- and K63-polyUb chains from protein substrates [116]. A recent study revealed USP33, located at the OMM, as a novel Parkin deubiquitinase; it is able to antagonize Parkin pro-mitophagy activity [118]. USP33 modulates Parkin self-ubiquitination at Lys435 and specifically removes K6-, K11-, K63and K48-linked Ub chains from Parkin.

Interestingly, a negative regulation of mitophagy by PTEN-long (PTEN-L), a novel protein phosphatase that acts dephosphorylating pSer-Ub, was recently shown. This activity keeps Parkin in the auto-inhibited conformation and inhibits its recruitment and activation in the OMM. In addition, PTEN-L has the ability to target pSer-Ub chains, leading to the impairing of the feed-forward mechanism of mitophagy [128,129].

\section{7. pUbl-Independent Mechanism of Parkin Activation, the Unexpected Plasticity of RING0 Binding Site}

One unsolved question regards the existence of molecular mechanisms other than PINK1-mediated phosphorylation for Parkin activation. The positive feed-forward amplification cycle of mitophagy also regulates Parkin in a phosphorylation-independent manner. Several studies demonstrated that Parkin recruitment to damaged mitochondria was not completely eliminated through the absence of the Ubl domain or Ser65 [85,130-132]. Moreover, the in vitro activation of unphosphorylated Parkin by pUb was observed, but the underlying mechanism still remains unclear [83].

A new study shows the pUb's ability to directly activate Parkin in the absence of the phosphorylation of its Ubl domain (Figure 1) [133]. This secondary mechanism for the activation of Parkin would be dependent on the RING0 pUbl-binding site. The binding of pUb to the RING0 pUbl-binding site enables pUb to act as a signal for Parkin recruitment to OMM and activation (Figure 1A). In this regard, RING0 would have a higher affinity for $\mathrm{pUb}$ than the pUbl domain. Similar to the PINK1-mediated activation of Parkin, the association of the second pUb to RING0 (Figure 1B-ii), instead of the pUbl domain (Figure 1B-i), leads to conformational reorganization, in which the catalytic RING2 domain is released. This mechanism reveals an amazing flexibility of RING0 for binding pUb and pUbl, suggesting the possibility that Parkin localization and activation may be controlled by other phosphoproteins that have the ability to bind RING0 or RING1 domains [133]. Thus, other activation mechanisms were proposed, but they require the support of structural analysis in future works. It was reported that Parkin increased its activity following Pololike, kinase-mediated phosphorylation at Ser378. In turn, Parkin activation leads to the ubiquitination of important regulators of mitosis, Cdh1 and Cdc20 [134]. Furthermore, Parkin phosphorylation at Ser131 and Tyr143 was catalyzed, respectively, by CDK5 (cyclin- 
dependent kinase), and c-Abl (Abelson tyrosine-protein kinase) reduced its ubiquitination activity [135-137].

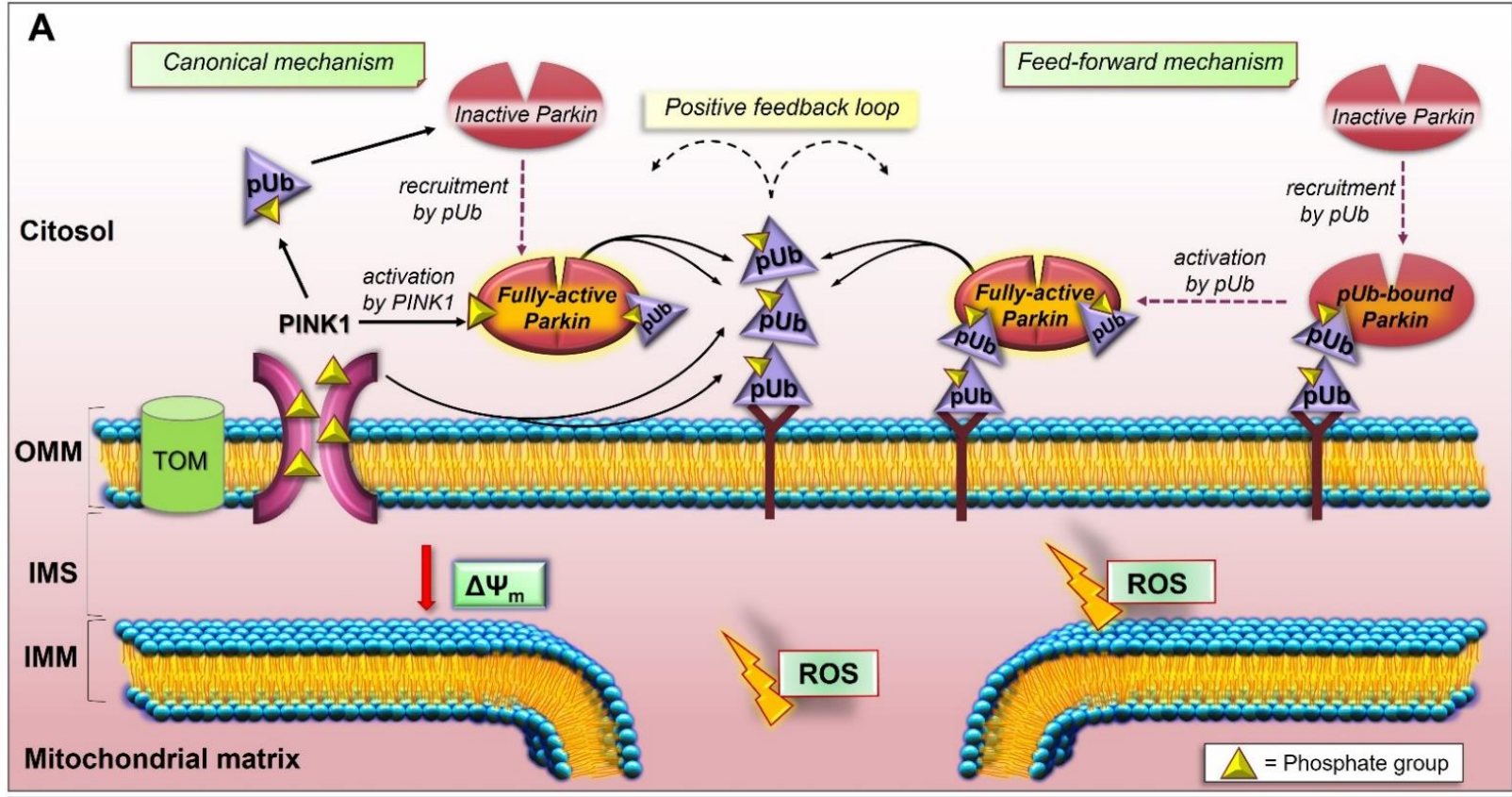

B

i) pUbl-driven Parkin activation (canonical)

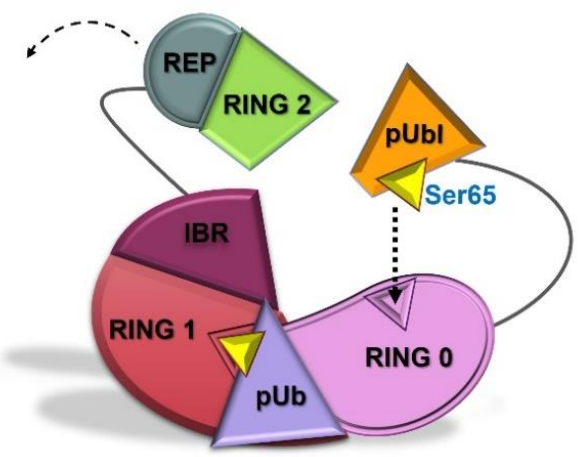

C

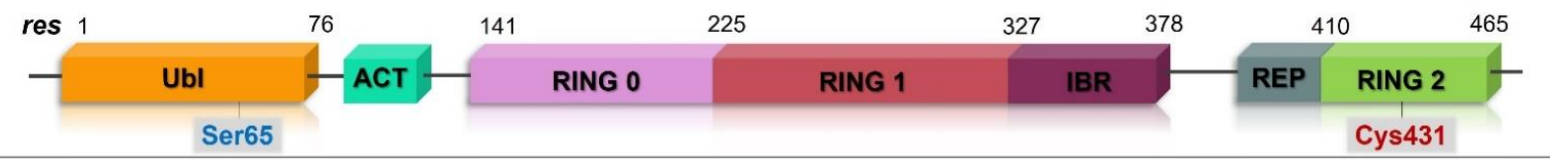

Figure 1. A working model representing simultaneous canonical and feed-forward mechanisms of Parkin activation. (A) Canonical mechanism: PINK1 activates Parkin directly by phosphorylating Parkin Ubl domain at Ser65 and indirectly through phosphorylation of Ub proteins at Ser65, relieving the autoinhibition of Parkin ligase. This enables Parkin to poly-ubiquitinate substrates on the OMM. These chains are then phosphorylated by PINK1 and act as docking sites for further recruitment and activation of Parkin (positive feedback loop); feed forward mechanism: PINK1-mediated phosphorylation of $\mathrm{Ub}$ on damaged mitochondria leads to the recruitment of latent Parkin. A second $\mathrm{pUb}$ acts as a fixed activation signal of Parkin leading to the conformational rearrangements which release its autoinhibition. Parkin-mediated addition of new $\mathrm{Ub}$ on the OMM gives rise to positive feedback cycle. OMM: outer mitochondrial membrane; IMS: intermembrane space; IMM: inner mitochondrial membrane. (B) Mechanisms of Parkin activation. (i) pUbl- or (ii) pUb-binding 
to RING0 domain causes conformational rearrangements resulting in REP and RING2 release determining fully activated Parkin. (C) Schematic representation of primary structure of Parkin with Ser65 phosphorylation site and Cys431 catalytic residue in Ubl and RING2 domains, respectively.

\subsection{PINK1 Processing and Stabilization}

In functional mitochondria with an unimpaired $\Delta \Psi_{\mathrm{m}}$, newly synthesized PINK1 is imported across the IMM by the outer- and inner-membrane translocase complexes, TOM and TIM, via the positively charged mitochondrial-targeting sequence. Therefore, PINK1 interacts with the surface receptors TOM20, TOM22, and TOM70; subsequently, it passes through the TOM40 translocation pore and IMM TIM23 complex $[98,138,139]$. Following the import, PINK1 is clipped in multiple ways: first, by the IMM-resident $\alpha$-cleaved form of PINK1/PGAM5-associated, rhomboid-like protease (PARL) within its transmembrane domain (between Ala103 and Phe104 residues); and second, by the mitochondrial processing peptidase (MPP) in the matrix [140-143]. The m-AAA protease AFG3L2, embedded in the IMM and with the active site facing the matrix, may act cooperatively with PARL, supporting its action [144]. The resulting cleaved (52kDa fragment) PINK1 has the Phe104 in its $\mathrm{N}$-terminus that acts as a targeting signal (type-2 N-degron) for the cytosolic E3 ubiquitin ligases (UBR1, UBR2, and UBR4). Thus, PINK1s (the short form of PINK1) is released into the cytoplasm, marked by ubiquitin, and ultimately degraded via the N-end rule pathway [145]. In this context, it was also proposed that the PINKs anchored in the OMM is polyubiquitinated and that Lys137 residue, instead of Phe104, plays a critical role in promoting PINK1 ubiquitination and its successive degradation via the proteasome system [146]. Nonetheless, the activation of the PINK1 kinase is prevented.

On the other hand, PINK1 is a sensor of mitochondrial damage, and when activated, triggers the mitophagy signal. PINK1 import is arrested upon mitochondrial uncoupling, and the enzyme is no longer subjected to protease cleavage. This results in the stabilization and activation of full-length (63 kDa) PINK1 in the OMM [47,48]. In this sense, the critical regulators for PINK1 import arrest and accumulation on the OMM are the OMS (OMM localization signal) domain of PINK1 and TOM7 [139], a subunit of TOM40 complex. To confirm this, PINK1 is imported and cleaved by OMA1 in depolarized mitochondria when TOM7 is absent [139]. Although the specific role of TOM7 is still unknown, it may be implicated in mediating the lateral release of the kinase from the TOM40 channel. Beyond the OMS domain, a specific negatively charged motif in PINK1 is also required to regulate the import [139]. As PINK1 builds on the OMM, its kinase activity is increased by dimerization and subsequent auto-phosphorylation at Ser228 and Ser402, which presumably occur in the TOM40 complex [147-149]. These steps enable PINK1 to phosphorylate the Ub and Ubl domain in Parkin. In addition to this, other mitochondrial proteins were recently reported to be phosphorylated by PINK1, including Mic60/Mitofilin and NDUFA10 [150,151].

\section{Functions of Mitophagy Receptors}

Under physiological and pathological conditions, mitophagy can occur independently of the presence of Parkin. These pathways rely on the intervention of receptors (BNIP3, NIX, FUNDC1, BCL2L13, FKBP8) constitutively localized in the OMM (via the C-terminal transmembrane (TM) domain) and containing a conserved LIR (LC3-interacting region) motif (at N-terminal region), which allows their association with phagophore on its LC3decorated membrane.

\section{(a) BNIP3 and NIX}

Although BNIP3 and NIX were initially reported to promote apoptosis and necrosis [152-155], these proteins are now well known to induce mitophagy. For instance, in response to hypoxia, they are similarly upregulated by HIF1 $\alpha$ to mediate mitophagy $[34,156-158]$. Stress signals induce both BNIP3 homodimerization (via its TM domain) and its integration into the OMM, essential processes for the efficient removal of mitochondria [157]. BNIP3LC3 interactions require BNIP3 phosphorylation at Ser17 and Ser24 [159]. In addition, myocyte lipotoxicity can activate NIX-mediated mitophagy. In this context, NIX-induced 
mitophagy is reversed by the PRKA/PKA-catalyzed phosphorylation of NIX at Ser212 (within the TM domain), leading to the retrotranslocation of the receptor from the sarcoplasmic reticulum and mitochondria to the cytosol [160]. NIX is involved in ensuring mitochondrial clearance during reticulocyte development [161] and is also required for mediating mitophagy following ischemia-reperfusion in the brain [158]. In CCCP-exposed cells, NIX mediates mitophagy by promoting GABARAP-L1 recruitment on the OMM and the binding of the latter with its LIR motif [162]. ROS (reactive oxygen species) generation induces the translocation of Rheb (a small GTPase) to mitochondria resulting in NIX/LC3 complex formation, which promotes the formation of mitophagosomes. It is noteworthy that the phosphorylation at the Ser34 and Ser35 sites near the LIR domain increases NIX affinity to LC3A/B and induces mitophagy [163]. NIX dimerization, which is modulated by C-terminal NIX phosphorylation, paired with BNIP3, is critical for initiating mitophagy [164]. A new study demonstrates that the kinase responsible for the phosphorylation of Ser17 in BNIP3 and Ser35 in NIX is ULK1 while TBK1 may be implicated in phosphorylating Ser24 and Ser34 in BNIP3 and NIX, respectively [165]. NIX and BNIP3 also act on multiple levels in PINK/Parkin-mediated mitophagy. In particular, BNIP3 contributes to PINK1 stabilization, facilitates the translocation of DRP1, and prevents BECN1/BCL-2 complex formation [156,166,167]. Parkin-mediated ubiquitination of NIX promotes NBR1 interaction with $\mathrm{Ub}$ and LC3/GABARAP leading to the generation of autophagosomes surrounding damaged mitochondria [168]. In depolarized mitochondria, NIX contributes to Parkin accumulation [169].

\section{(b) FUNDC1}

Hypoxia-induced mitophagy is also regulated by the activity of the mitophagy receptor FUNDC1, which contains an LIR motif and three TM domains [170]. Under hypoxia conditions, mitochondrial E3 ligase MITOL can regulate the protein expression levels of FUNDC1 [171]. In order to avoid uncontrolled mitophagy, MITOL-mediated ubiquitination of FUNDC1 at Lys119 targets the receptor for proteasomal degradation [171]. FUNDC1 phosphorylation on residues Tyr18 and Ser13 near the LIR domain also contributes to regulating FUNDC1-LC3 interactions. Under basal conditions, FUNDC1 is inactivated through the phosphorylation of Tyr18 and Ser13 residues by Src tyrosine kinase and CK2 (casein kinase2), respectively. Hypoxia conditions inactivate Src causing the reduced phosphorylation of Tyr18, FUNDC1 binding with LC3, and the formation of the mitophagosome [170]. Under stress conditions, the dephosphorylation of Ser13 by Ser/Thr phosphatase PGAM5 stabilizes FUNDC1-LC3 interactions, promoting mitophagy [172]. By contrast, PGAM5FUNDC1 interactions are inhibited during normoxia conditions, as BCL2L1/Bcl-xL is associated with phosphatase, preventing the dephosphorylation of FUNDC1 Ser13 and mitochondria removal [173]. Interestingly, an enhanced association between FUNDC1 and LC3 is induced by the ULK1-mediated phosphorylation of FUNDC1 at Ser17 near the LIR domain [174]. During cardiac progenitor cell differentiation, FUNDC1- and NIX-mediated mitophagy is essential in mediating the remodeling of the mitochondrial network [175].

\section{(c) BCL2L13, FKBP8, AMBRA-1}

In mammalian cells, additional autophagy receptors were studied, although were less well characterized, including BCL2L13, FKBP8 and AMBRA-1. BCL2L13 seems to mediate mitophagy by regulating mitochondrial fission [176] and by interacting with ULK1 [177]. FKBP8 mediates mitochondrial fragmentation and Parkin-independent mitophagy by the recruitment of LC3A [178]. AMBRA1 (autophagy and Beclin 1 regulator 1) can associate with LC3 via an LIR motif and can also induce Parkin-independent and -dependent mitophagy $[179,180]$. In SH-SY5Y cells, AMBRA1-mediated mitophagy protects against apoptosis induced by redox status alterations [181]. 


\subsection{Other Promoters of Mitophagy: Cardiolipin and Novel E3 Ligases}

Recent findings identified cardiolipin (a dimeric phospholipid of the IMM) as a positive regulator of mitophagy [182]. It can translocate to the OMM upon mitochondrial damage and associate with LC3 to promote mitophagy $[182,183]$.

In addition, novel regulators of Parkin-independent mitophagy were recently identified, including other E3 ligases such as MUL1, ARIH1, CIAP1/2, Gp78, and TRAF2, and the Synuclein alpha-interacting protein (Synphilin-1) [184-189]. In cancer cells, where ARIH1 (Ariadne RBR E3 Ub protein ligase 1) is highly expressed and Parkin is often downregulated, the Ub ligase activity of ARIH1 promotes mitophagy in a PINK1-dependent manner, contributing to chemotherapy resistance [188]. In cultured cells and rat brain tissues, the PINK1-mediated recruitment of synphilin-1 to mitochondria promotes the SIAH1-mediated ubiquitination of mitochondrial substrates, which results in the recruitment of LC3 for autophagosome formation [187]. Finally, in a PD model MUL1 can rescue the PINK1- and Parkin-mutant phenotypes, compensating for PINK1/Parkin loss [186].

\subsection{Autophagy Adaptors Linking to PINK1-Parkin-Mediated Mitophagy}

During Ub-mediated selective autophagy, including PINK1-Parkin-mediated mitophagy, autophagy receptors such as p62/SQSTM1, NBR1, NDP52, Tax1BP1, and OPTN play crucial roles in the recognition and autophagic encapsulation of target cargoes [190]. The autophagy adaptors have both an LIR domain and Ub-binding region that interact with the $\mathrm{Ub}$ chains associated with the cargoes. They are all phosphorylated by TBK1 (TANK-Binding Kinase1), increasing their binding affinity to Ub-chains and ATG8 proteins [191,192]. In particular, OPTN is phosphorylated on Ser177 to enhance the binding affinity with LC3 [193] and on Ser 473 and Ser 513 to enhance its ubiquitin-chain binding activity [191].

\subsection{The Linear Sequence of Mitophagosome Synthesis}

Canonical mitophagy implicates the selective engulfment of damaged mitochondria into autophagosomes. In turn, autophagosomes quickly fuse with lysosomes allowing for complete mitochondrial degradation. Historically, mitophagophore formation was thought of as a linear sequence described below.

Mitophagosome initiation requires the coordinated recruitment of the ULK complex (composed of ULK1, FIP200, ATG13, and ATG101) and ATG9-containing vesicles on ER-associated membranes $[194,195]$. These regions are focal points for the subsequent recruitment of the vacuolar protein sorting (VPS)34 complex (consisting of the phosphatidylinositol 3-kinase (PI3K) VPS34, and the adaptors ATG14, VPS15, and Beclin1), which produces PI3P $[196,197]$ on DFCP1 (double FYVE-containing protein 1)-positive ER segments known as "omegasomes" [198]. Omegasomes amplify the local PI3P signals, thus attracting WIPI1/2 that recruit additional ATGs (including ATG5-12-16), as well as the lipidation machinery that covalently modifies ATG8s (LC3 and GABARAP subfamilies) with PE (phosphatidylethanolamine) $[199,200]$. As part of the autophagosomal membrane, the PE-conjugated ATG8 family acts as a tether between cargo and phagophore [201]. Mitophagy then requires the elongation and maturation of the phagophore through lipids addition. Once the endosomal sorting complex is in place, the autophagosome is closed and sorted towards the lysosomes [202].

However, recent studies revealed some vulnerabilities in this model that are discussed later in more detail.

\subsection{Mitophagosome Synthesis: Redundancy and Positive Feedback Signals, and the Role of mTORC1}

Mitophagosome synthesis is far from being a linear sequence of events since it seems to involve amplification loops and feedback signals [191]. In this sense, recent studies also revealed a different sequence of reactions with respect to starvation-induced autophagy (mTORC1-ULK1-LC3), a different implication of mTORC1, and new ways to fine-tune mitophagy processes. In addition, reports suggest that mitophagy depends not only on 
pre-existing membranes but also on the de novo synthesis of the autophagosome via the activation of early components.

Although mTORC1 is the master regulator during starvation-induced autophagy [203,204], its involvement during mitophagy has not yet been clarified. Some studies suggested that PINK1-Parkin may require the inactivation of mTOR [205,206]. Consistent with this, the inhibition of PINK1-Parkin-mediated mitophagy is induced by mTORC1 hyperactivation [206-208]. Additionally, hypoxia conditions can reduce mTORC1 activity [209]. On the other hand, during Invermectin-induced mitophagy, mTORC1 activity does not seem to change [55,189,210], and mTORC1 overexpression does not affect selective autophagy [71]. The functional significance of LC3 during mitophagy is also still debatable, as well as the coordinated recruitment of early autophagy structures (ULK complex and ATG9 unit) on ER-associated membranes. For instance, in cardiomyocytes and HeLa cells, a non-canonical mitophagy pathway not requiring LC3 lipidation was reported to occur upon starvation and hypoxia $[38,211]$. Following the loss in $\Delta \Psi_{\mathrm{m}}$, Uthe LK1 complex and ATG9 unit are independently associated with dysfunctional mitochondria, even when membrane-bound LC3 is lacking [194], and in an adaptor-dependent manner [190].

Although all five autophagy receptors can mediate the recruitment of ATG8-associated membranes during mitophagy, only OPTN and NDP52 are crucial for mitochondrial clearance. The generation of phospho-Ub signals on the OMM is fully dependent on PINK1 but does not fully require Parkin activity. Therefore, PINK1 is able to recruit NDP52 and OPTN independently from Parkin. In this sense, PINK1 acts as both a damage sensor and effector, whereas Parkin would amplify rather than trigger the mitophagy signal [190]. NDP52 recruitment to ubiquitinated mitochondria is independent of LC3, but it is enough for the initiation of phagophore [212]. Indeed, OPTN and NDP52 can significantly amplify the mitophagy via the ATG8-dependent positive feedback loop [213]. During mitophagy, the existence of multiple initiation events was suggested by the fact that ATG13 and OPTN could interact with mitochondria in a discontinuous oscillatory modality [189]. NDP52 promotes both the recruitment and activation of ULK1 on cargo through the association of the NDP52-FIP200/ULK1 complex [71]. Additionally, in addition to binding ATG8 proteins, OPTN interacts with ATG9A molecules. Therefore, the recruitment of both OPTN and NDP52 on the ubiquitinated mitochondria are critical in promoting de novo autophagosomal membrane formation, almost to Ub-positive cargo. Therefore, Parkinmediated mitophagy seems to rely on the NDP52-ULK1/LC3 and OPTN-ATG9/LC3 sequence of reactions.

\subsection{Autophagosome Elongation and Closure}

Mitophagy requires the expansion of phagophore membranes. The recruitment of GTPase-activating proteins (GAPs) for initiating RAB7 cycling plays a critical role in this process. Cargo ubiquitination by Parkin recruits RABGFE1, which triggers the endosomal Rab GTPase cascade, including RAB5 and MON1/CCZ1 [214]. In turn, MON1/CCZ1 facilitates the recruitment of RAB7A to mitochondria, and RAB7A promotes ATG9 vesicle assembly to the autophagosome formation area. TBC1D15/D17 and TBC1D5 act as mitochondrial GAPs for Rab GTPase and target ATG8/ATG9 family proteins around damaged mitochondria by modulating Rab7 activity, in order to recruit the isolation membrane $[215,216]$. TBK1-mediated phosphorylation of RAB7A assists in bringing ATG9 vesicles to mitochondria [217]. Thus, these findings suggest the central role played by the endosomal Rab cycles during mitophagy. The removal of dysfunctional mitochondria requires autophagosome-lysosome fusion. Although the loss of ATG8 family members does not abrogate autophagosome formation, ATG8 proteins are essential for autophagosomelysosome fusion [212] and degradation of the inner autophagosomal membrane [218].

\subsection{AMPK/ULK1 Axis in Mitophagy Cascade}

In response to mitochondrial damage, as well as under energetic stress, the AMPK complex (consisting of a catalytic $\alpha$, a scaffolding $\beta$, and a regulatory $\gamma$ subunit) acts as a 
sensor. It engages downstream effectors implicated in metabolic processes, autophagy, and in different aspects of mitochondrial homeostasis, including biogenesis, dynamics, and, ultimately, the clearance of damaged mitochondria, to restore homeostasis. Canonically, a radical increase in the cellular AMP/ATP ratio triggers the full activation of AMPK due to AMP / ADP binding to the $\gamma$ subunit and the subsequent phosphorylation of the Thr172 by the upstream kinase liver kinase B1 (LKB1) [57]. The direct link of AMPKmediated, energy-sensing function to the autophagy process is represented by the Ser/Thr kinase ULK1 [219]. In addition to ULK1, AMPK also interacts with ATG9 and components of the Class III PI3K complex 1 of the autophagy pathway [57]. ULK1 represents the most upstream activator of the autophagic pathway and is extensively phosphorylated by AMPK [203,220-222]. ULK1 is a core constituent of the autophagy pre-initiation complex with ATG101, ATG13, and FIP200. All of these components are substrates of ULK1 kinase activity as well as ULK1 itself. Additional targets of ULK1 were reported, including AMBRA1, VPS34, syntenin-1, TAB2, Raptor, FUNDC1, BNIP3, ATG14, ATG16L, Sec16a, and Sec23a [165,174,223-232]. In addition to the autophagy activation, it is becoming more evident that the AMPK/ULK1 axis plays a crucial role in promoting mitophagy $[233,234]$. Indeed, ULK1- or AMPK-deficient cell lines exhibit an increased accumulation of morphologically altered mitochondria, suggesting that the AMPK-dependent phosphorylation of ULK1 is crucial for the selective clearance of mitochondria $[220,235,236]$. In this regard, AMPK-mediated ULK1 phosphorylation at Ser555 regulates ULK1 translocation to mitochondria and mitophagy [234,237]. As the proton ionophore CCCP is a strong inducer of PINK1-Parkin-mediated mitophagy and AMPK by ATP depletion, new studies are developing in order to establish which relationship links PINK/Parkin pathway with the AMPK/ULK1 axis. In this regard, exactly how Parkin first senses problems with mitochondria and how specific phosphorylation events orient towards mitophagy remain to be defined [238]. Another important question is how AMPK regulates mitophagy in skeletal muscle. In this regard, new PINK1-Parkin-independent mechanisms and the activation of specific, subcellular AMPK pools were reported [239-241].

\subsection{The Early Role of the AMPK/ULK1 Axis in Triggering the Rapid Activation of Parkin}

As described above, although it is well known that Parkin can sense mitochondrial stress and promote mitophagy, the initial input in dictating the earliest Parkin recruitment remains to be clarified. In this sense, a model revealing the implication of the AMPK-ULK1 axis in starting the first translocation of Parkin onto the OMM was recently proposed in vivo and in vitro (Figure 2A) [238]. In particular, Parkin was reported as a novel ULK1 substrate. Under mitochondrial stress (exposure to CCCP or valinomycin), the immediate activation of cytosolic AMPK (within $2 \mathrm{~min}$ ) leads to the phosphorylation of its downstream substrates, including ULK Ser555, Raptor Ser 792, MFF Ser146, and ACC Ser79. At the same time, ULK1 activation results in the specific phosphorylation of Parkin Ser108 (P-Parkin-108), an event that seems to be localized in the cytoplasmic region [238]. This phosphorylation falls in a new highly conserved region named the ACT element (activating element). This short region is localized in the flexible linker between the UBL and RING0 domains and is suggested to be critical for Parkin activation (Figure 2A, Top) [79]. Interestingly, phosphoproteomic analyses previously revealed the phosphorylation of Parkin Ser108 in brown fat, although the kinase responsible for this event was not identified identified [242]. In parallel to P-Parkin108, phosphorylations of Beclin Ser30 and ATG16L1 Ser278, two ULK1 substrates [224,230], were also observed. Within 10 min of CCCP exposure, the recruitment of AMPK and ULK1 to mitochondria leads to MFF phosphorylation and mitochondrial fission. Only at later time points (after $30 \mathrm{~min}$ ) does the phosphorylation of Parkin Ser65 occur. This event coincides with the ubiquitination of the substrates of Parkin, CISD1 and Mfn2, and TBK activation at Ser172 [238]. This study demonstrates that the rapid and greatest PINK1-mediated phosphorylation of Parkin Ser65 requires the ULK1-dependent phosphorylation of Parkin at Ser108. In addition, these findings highlight the crucial and early role played by the AMPK/ULK1 axis in mitophagy and place Parkin regulation downstream of AMPK/ULK1, revealing a new route to modulating Parkin. 
The direct association of Parkin with ULK1, and thus AMPK, enriches the scenario of possible connections between AMPK and mitochondria.

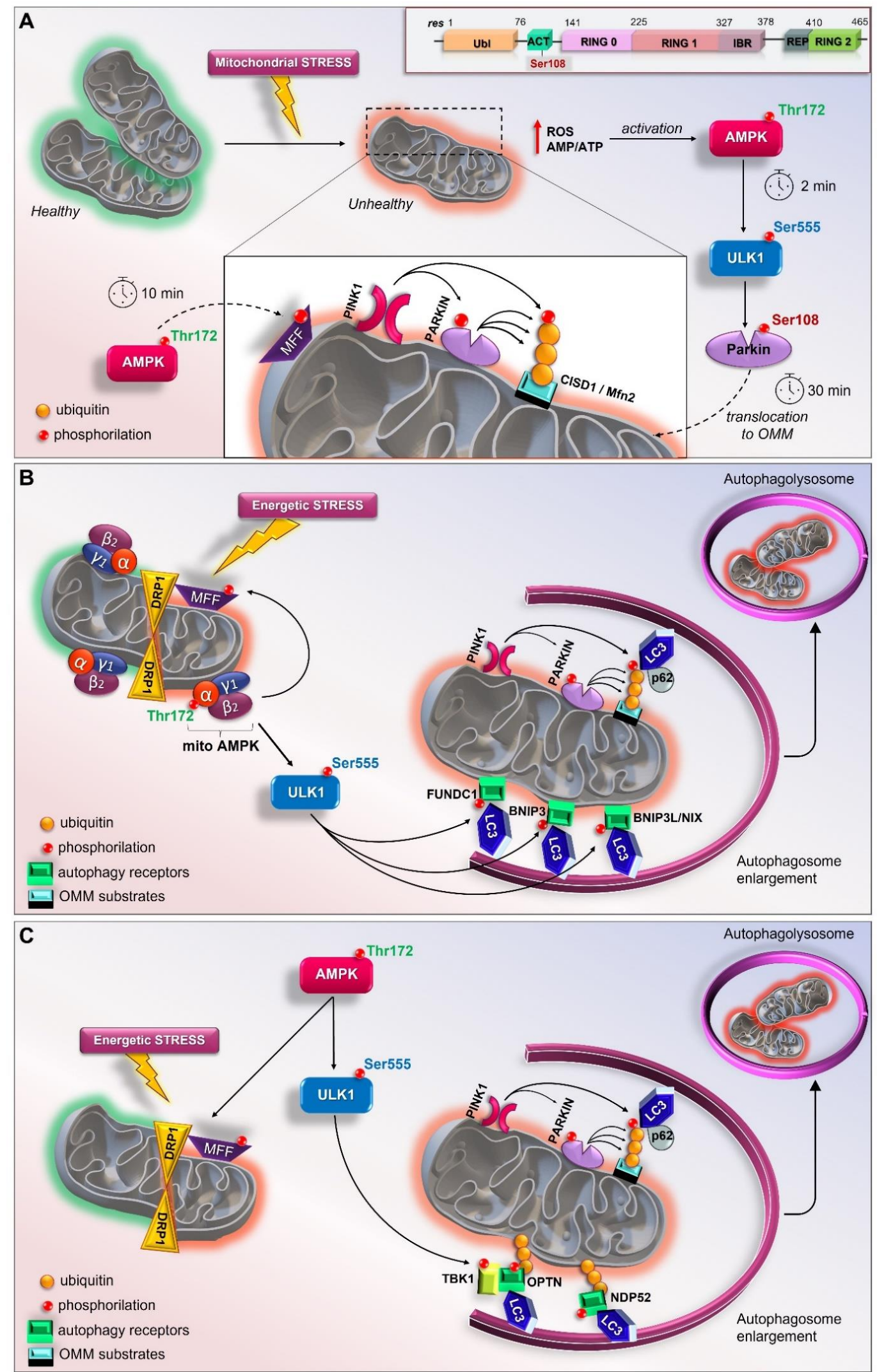

Figure 2. New current models of AMPK/ULK1-mediated mitophagy. (A) Top, schematic representation of primary structure of Parkin showing ACT element with Ser108 residue. In mouse livers and primary 
hepatocytes AMP/ULK1 axis triggers the rapid activation of Parkin (by Hung et al.) [238]. Upon mitochondrial depolarization, AMP/ATP imbalance and increases in mtROS immediately activate AMPK/ULK1 signaling. Therefore, in the cytoplasm ULK1 phosphorylates Parkin at Ser108 within 2 min of depolarization treatment. Later, AMPK phosphorylates MFF to induce mitochondrial fission and PINK1 phosphorylates Parkin at Ser65; (B) In skeletal muscle, mitoAMPK regulates the spatial specificity of mitophagy in a context of mitochondrial remodeling (by Drake et al.) [241]. Following energetic stress, mitoAMPK is activated in vivo and promotes ULK1-mediated formation of autophagosome which fuse with lysosomes to allow the complete mitochondrial degradation; (C) In C2C12 myotubes, AMPK coordinates mitophagy through mitochondrial fission via MFF and TBK1-mediated autophagosomal engulfment via ULK1 activation (by Seabright et al.) [239].

\subsection{Other Scenarios of AMPK- and ULK1-Mediated Mitophagy}

The interplay between PINK1-Parkin signaling and AMPK was also demonstrated in cardiomyocytes [243]. Therefore, the AMPK $\alpha 2$-mediated phosphorylation of PINK1 at Ser495 stimulates the PINK1-Parkin-SQSTM1 signaling implicated in cardiac mitophagy, and these events are essential for preventing the progression of heart failure. Parkin was also reported as an AMPK substrate [244]. In particular, Parkin is phosphorylated (at Ser9) and activated by AMPK to trigger RIPK3 polyubiquitination and reduce cell death during necroptosis.

The direct assembly of the autophagosome to the deranged mitochondrion is another mechanism by which AMPK is able to regulate mitophagy, independently of ULK1 [233]. In particular, the association of the AMPK complex with dysfunctional mitochondria, via the N-myristoylation of AMPKß subunits, promotes the recruitment of the ATG16 complex to the damaged regions and triggers the assembly of the autophagosome. Additionally, in leukemia stem cells (LSCs), the mitochondrial stress derived from oncogenic transformation triggers AMPK/FIS1-mediated mitophagy in an effort to keep the healthy mitochondria needed for LSCs self-renewal and survival [245]. In hepatocytes, AMPK upregulates mitophagy by increasing UQCRC2 (ubiquinol-cytochrome c reductase core protein 2) protein expression levels through the activation of NFE2L2/NRF2 (nuclear factor, erythroid like 2) [246].

ULK1, for its part, is an active element of the mitophagic integrated system and its crucial role was determined. In some cases, it may additionally connect mitophagy modulators with the PINK/Parkin system. Indeed, ULK1 can directly phosphorylate mitophagy receptors such as FUNDC1, BNIP3, NIX, BCL2L13 and VCP/p97 [165,174,177]. In particular, $\mathrm{VCP} / \mathrm{p} 97$ is recruited to regions affected by Parkin ubiquitination. The ULK1-mediated phosphorylation of FUNDC1 at Ser17 promotes FUNDC1/LC3 interaction and mitophagy. In mammalian cells, BCL2L13 induces mitophagy by forming a complex with ULK1 and LC3B [176,177]. Moreover, ULK1 specifically promotes mitophagy by phosphorylating NIX and BNIP3 on Ser 35 and Ser17, respectively, to stimulate their interaction with LC3. The phosphorylation of BNIP3 also leads to its stabilization due to the inhibition of proteasomal turnover [165].

\subsection{The Mitochondrial Pool of AMPK (mitoAMPK) Governs the Spatial Specificity of Energetic Stress-Induced Mitophagy}

AMPK-mediated ULK1 phosphorylation at Ser555 regulates mitophagy in different cell types, including human acute myeloid leukemia stem cells, and mouse skeletal muscle $[237,247]$ In particular, it was demonstrated that a single bout of exercise triggers mitophagy in skeletal muscle during the recovery period [237] in a PINK1-independent manner [37]. The direct phosphorylation of the mitochondrial fission factor (MFF), which triggers mitochondrial fragmentation before mitophagy, by AMPK also demonstrates a critical role of the kinase in mitochondrial dynamics [248]. Zong et al. [249] demonstrated that distinct thresholds of energetic stress can trigger different compartmentalized pools of AMPK. In addition, different heterotrimeric complexes of AMPK may show specificity for 
different targets suggesting that this spatial activation is the key for managing energy stress. Consistent with this, Drake et al. [241] demonstrated the presence of specific isoforms of mitoAMPK in different tissues in mice and humans. In particular, the isoforms of AMPK $\alpha 1$, $\alpha 2, \beta 2$, and $\gamma 1$ are physically associated with the OMM, and this mitochondrial localization is conserved in human skeletal muscle and heart. Additionally, different energetic stresses (e.g., ischemia, muscle contractions, and treadmill running) can activate mitoAMPK in vivo and this event is required for mitophagy (Figure 2B). Indeed, the inhibition of mitoAMPK activity reduces exercise-induced mitophagy.

In skeletal muscle, AMPK is emerging as a crucial regulator of mitophagy, while experimental evidence linking the PINK1-Parkin pathway to the selective removal of mitochondria is limited [240]. Thus, in C2C12 myotubes, energetic stress induces AMPK-mediated mitochondrial fission via the direct phosphorylation of MFF, and TBK1 phosphorylation, possibly via ULK1 activated by AMPK, in a PINK1-Parkin-independent way. In this context, AMPK promotes mitophagy by increasing, on the one hand, mitochondrial fission, and on the other, TBK1-mediated mitochondrial autophagosome engulfment (Figure 2C [239]).

\section{Conclusions and Future Perspectives}

Over the past decade, our understanding of the molecular mechanisms governing mitophagy has considerably increased, not only due to the levels of complexity of the pathways involved but also because a lack of mitophagy was associated with numerous aging-related diseases. Although detailed mechanistic studies revealed the importance of PINK1-Parkin signaling in regulating mitophagy, multiple molecular players and redundant pathways are also involved in managing mitochondrial removal. Thus, it is now clear that the modulation of basal mitophagy does not require the involvement of the PINK1-Parkin axis, which may be more related to the mitochondrial removal in response to specific stresses. In renewing our understanding of the molecular mechanism underlying mitophagy, the emerging role of AMPK is also becoming increasingly crucial in light of its ability to promote the early and major step of mitophagy (by the sequence AMPK-ULK1Parkin). PINK1 and Parkin are activated by complete mitochondrial depolarization while AMPK and ULK1 require mild mitochondrial perturbations (e.g., metformin). Therefore, it will be interesting to delineate the role and function of the AMPK/ULK1 axis in the activation of Parkin. Indeed, they are shared elements in different diseases including neurodegeneration, cancer and diabetes. This may allow the expansion of the homeostatic and/or pathogenic conditions in which Parkin plays a critical role in maintaining mitochondrial health. Altogether, these issues may aid to design novel therapeutic approaches to target pathophysiological processes correlated with mitochondrial dysfunction.

Author Contributions: R.I., G.C. and S.P. have made substantial contributions to the conception and design of the work. R.I. and S.P. wrote the original draft and created the figures. All authors contributed to the discussion of the content, reviewed and edited the manuscript before submission. The authors read and approved the final manuscript. All authors have read and agreed to the published version of the manuscript.

Funding: This work was supported by a grant from MIUR (Ministero dell'Istruzione, dell'Università e della Ricerca, Italy) (grant number CUP E11I18000300005) to Roberto Iorio, and Biolabo to Giuseppe Celenza.

Institutional Review Board Statement: Not applicable.

Informed Consent Statement: Not applicable.

Data Availability Statement: Not applicable.

Conflicts of Interest: The authors declare no conflict of interest. 


\section{References}

1. Glancy, B.; Hartnell, L.M.; Combs, C.A.; Femnou, A.; Sun, J.; Murphy, E.; Subramaniam, S.; Balaban, R.S. Power Grid Protection of the Muscle Mitochondrial Reticulum. Cell Rep. 2017, 19, 487-496. [CrossRef]

2. Raffaello, A.; Mammucari, C.; Gherardi, G.; Rizzuto, R. Calcium at the Center of Cell Signaling: Interplay between Endoplasmic Reticulum, Mitochondria, and Lysosomes. Trends Biochem. Sci. 2016, 41, 1035-1049. [CrossRef] [PubMed]

3. Csordás, G.; Weaver, D.; Hajnóczky, G. Endoplasmic Reticulum-Mitochondrial Contactology: Structure and Signaling Functions. Trends Cell Biol. 2018, 28, 523-540. [CrossRef]

4. Kalkavan, H.; Green, D.R. MOMP, cell suicide as a BCL-2 family business. Cell Death Differ. 2018, 25, 46-55. [CrossRef] [PubMed]

5. Spinelli, J.B.; Haigis, M.C. The multifaceted contributions of mitochondria to cellular metabolism. Nat. Cell Biol. 2018, 20, 745-754. [CrossRef]

6. Lackner, L.L. The Expanding and Unexpected Functions of Mitochondria Contact Sites. Trends Cell Biol. 2019, 29, 580-590. [CrossRef] [PubMed]

7. $\quad$ Rhee, H.-W.; Zou, P.; Udeshi, N.D.; Martell, J.D.; Mootha, V.K.; Carr, S.A.; Ting, A.Y. Proteomic Mapping of Mitochondria in Living Cells via Spatially Restricted Enzymatic Tagging. Science 2013, 339, 1328-1331. [CrossRef] [PubMed]

8. Wong, H.-S.; Dighe, P.A.; Mezera, V.; Monternier, P.-A.; Brand, M.D. Production of superoxide and hydrogen peroxide from specific mitochondrial sites under different bioenergetic conditions. J. Biol. Chem. 2017, 292, 16804-16809. [CrossRef] [PubMed]

9. Sun, Y.; Lu, Y.; Saredy, J.; Wang, X.; Drummer IV, C.; Shao, Y.; Saaoud, F.; Xu, K.; Liu, M.; Yang, W.Y.; et al. ROS systems are a new integrated network for sensing homeostasis and alarming stresses in organelle metabolic processes. Redox Biol. 2020, $37,101696$. [CrossRef]

10. Scheibye-Knudsen, M.; Fang, E.F.; Croteau, D.L.; Wilson, D.M.; Bohr, V.A. Protecting the mitochondrial powerhouse. Trends Cell Biol. 2015, 25, 158-170. [CrossRef]

11. Bohovych, I.; Chan, S.S.L.; Khalimonchuk, O. Mitochondrial Protein Quality Control: The Mechanisms Guarding Mitochondrial Health. Antioxid. Redox Signal. 2015, 22, 977-994. [CrossRef]

12. Ploumi, C.; Daskalaki, I.; Tavernarakis, N. Mitochondrial biogenesis and clearance: A balancing act. FEBS J. 2017, 284, 183-195. [CrossRef] [PubMed]

13. Ni, H.-M.; Williams, J.A.; Ding, W.-X. Mitochondrial dynamics and mitochondrial quality control. Redox Biol. 2015, 4, 6-13. [CrossRef] [PubMed]

14. Eisner, V.; Picard, M.; Hajnóczky, G. Mitochondrial dynamics in adaptive and maladaptive cellular stress responses. Nat. Cell Biol. 2018, 20, 755-765. [CrossRef]

15. Petricca, S.; Flati, V.; Celenza, G.; Di Gregorio, J.; Lizzi, A.R.; Luzi, C.; Cristiano, L.; Cinque, B.; Rossi, G.; Festuccia, C.; et al Tebuconazole and Econazole Act Synergistically in Mediating Mitochondrial Stress, Energy Imbalance, and Sequential Activation of Autophagy and Apoptosis in Mouse Sertoli TM4 Cells: Possible Role of AMPK/ULK1 Axis. Toxicol. Sci. 2019, 169, 209-223. [CrossRef]

16. Fiorese, C.J.; Schulz, A.M.; Lin, Y.-F.; Rosin, N.; Pellegrino, M.W.; Haynes, C.M. The Transcription Factor ATF5 Mediates a Mammalian Mitochondrial UPR. Curr. Biol. 2016, 26, 2037-2043. [CrossRef]

17. Smyrnias, I.; Gray, S.P.; Okonko, D.O.; Sawyer, G.; Zoccarato, A.; Catibog, N.; López, B.; González, A.; Ravassa, S.; Díez, J.; et al. Cardioprotective Effect of the Mitochondrial Unfolded Protein Response During Chronic Pressure Overload. J. Am. Coll. Cardiol. 2019, 73, 1795-1806. [CrossRef]

18. Quiles, J.M.; Gustafsson, Å.B. Mitochondrial Quality Control and Cellular Proteostasis: Two Sides of the Same Coin. Front. Physiol. 2020, 11, 515. [CrossRef] [PubMed]

19. Münch, C. The different axes of the mammalian mitochondrial unfolded protein response. BMC Biol. 2018, 16, 81. [CrossRef] [PubMed]

20. Pickles, S.; Vigié, P.; Youle, R.J. Mitophagy and Quality Control Mechanisms in Mitochondrial Maintenance. Curr. Biol. 2018, 28, R170-R185. [CrossRef]

21. Muñoz-Carvajal, F.; Sanhueza, M. The Mitochondrial Unfolded Protein Response: A Hinge Between Healthy and Pathological Aging. Front. Aging Neurosci. 2020, 12, 300. [CrossRef] [PubMed]

22. Palikaras, K.; Lionaki, E.; Tavernarakis, N. Mechanisms of mitophagy in cellular homeostasis, physiology and pathology. Nat. Cell Biol. 2018, 20, 1013-1022. [CrossRef] [PubMed]

23. Smith, M.D.; Harley, M.E.; Kemp, A.J.; Wills, J.; Lee, M.; Arends, M.; von Kriegsheim, A.; Behrends, C.; Wilkinson, S. CCPG1 Is a Non-canonical Autophagy Cargo Receptor Essential for ER-Phagy and Pancreatic ER Proteostasis. Dev. Cell 2018, 44, 217-232.e11. [CrossRef] [PubMed]

24. Ravenhill, B.J.; Boyle, K.B.; von Muhlinen, N.; Ellison, C.J.; Masson, G.R.; Otten, E.G.; Foeglein, A.; Williams, R.; Randow, F. The Cargo Receptor NDP52 Initiates Selective Autophagy by Recruiting the ULK Complex to Cytosol-Invading Bacteria. Mol. Cell 2019, 74, 320-329.e6. [CrossRef] [PubMed]

25. Turco, E.; Witt, M.; Abert, C.; Bock-Bierbaum, T.; Su, M.-Y.; Trapannone, R.; Sztacho, M.; Danieli, A.; Shi, X.; Zaffagnini, G.; et al. FIP200 Claw Domain Binding to p62 Promotes Autophagosome Formation at Ubiquitin Condensates. Mol. Cell 2019, 74, 330-346.e11. [CrossRef]

26. Le Guerroué, F.; Eck, F.; Jung, J.; Starzetz, T.; Mittelbronn, M.; Kaulich, M.; Behrends, C. Autophagosomal Content Profiling Reveals an LC3C-Dependent Piecemeal Mitophagy Pathway. Mol. Cell 2017, 68, 786-796.e6. [CrossRef] 
27. McWilliams, T.G.; Prescott, A.R.; Allen, G.F.G.; Tamjar, J.; Munson, M.J.; Thomson, C.; Muqit, M.M.K.; Ganley, I.G. mito-QC illuminates mitophagy and mitochondrial architecture in vivo. J. Cell Biol. 2016, 214, 333-345. [CrossRef]

28. Sun, N.; Malide, D.; Liu, J.; Rovira, I.I.; Combs, C.A.; Finkel, T. A fluorescence-based imaging method to measure in vitro and in vivo mitophagy using mt-Keima. Nat. Protoc. 2017, 12, 1576-1587. [CrossRef] [PubMed]

29. Lee, J.J.; Sanchez-Martinez, A.; Zarate, A.M.; Benincá, C.; Mayor, U.; Clague, M.J.; Whitworth, A.J. Basal mitophagy is widespread in Drosophila but minimally affected by loss of Pink1 or parkin. J. Cell Biol. 2018, 217, 1613-1622. [CrossRef]

30. McWilliams, T.G.; Prescott, A.R.; Montava-Garriga, L.; Ball, G.; Singh, F.; Barini, E.; Muqit, M.M.K.; Brooks, S.P.; Ganley, I.G Basal Mitophagy Occurs Independently of PINK1 in Mouse Tissues of High Metabolic Demand. Cell Metab. 2018, 27, 439-449.e5. [CrossRef]

31. Sun, N.; Yun, J.; Liu, J.; Malide, D.; Liu, C.; Rovira, I.I.; Holmström, K.M.; Fergusson, M.M.; Yoo, Y.H.; Combs, C.A.; et al. Measuring In Vivo Mitophagy. Mol. Cell 2015, 60, 685-696. [CrossRef] [PubMed]

32. Esteban-Martínez, L.; Sierra-Filardi, E.; McGreal, R.S.; Salazar-Roa, M.; Mariño, G.; Seco, E.; Durand, S.; Enot, D.; Graña, O.; Malumbres, M.; et al. Programmed mitophagy is essential for the glycolytic switch during cell differentiation. EMBO J. 2017, 36, 1688-1706. [CrossRef] [PubMed]

33. Esteban-Martínez, L.; Boya, P. BNIP3L/NIX-dependent mitophagy regulates cell differentiation via metabolic reprogramming. Autophagy 2018, 14, 915-917. [CrossRef] [PubMed]

34. Ney, P.A. Mitochondrial autophagy: Origins, significance, and role of BNIP3 and NIX. Biochim. Biophys. Acta-Mol. Cell Res. 2015, 1853, 2775-2783. [CrossRef]

35. Zhang, W.; Ma, Q.; Siraj, S.; Ney, P.A.; Liu, J.; Liao, X.; Yuan, Y.; Li, W.; Liu, L.; Chen, Q. Nix-mediated mitophagy regulates platelet activation and life span. Blood Adv. 2019, 3, 2342-2354. [CrossRef]

36. Sato, K.; Sato, M. Multiple ways to prevent transmission of paternal mitochondrial DNA for maternal inheritance in animals. J. Biochem. 2017, 162, 247-253. [CrossRef] [PubMed]

37. Drake, J.C.; Laker, R.C.; Wilson, R.J.; Zhang, M.; Yan, Z. Exercise-induced mitophagy in skeletal muscle occurs in the absence of stabilization of Pink1 on mitochondria. Cell Cycle 2019, 18, 1-6. [CrossRef]

38. Saito, T.; Nah, J.; Oka, S.; Mukai, R.; Monden, Y.; Maejima, Y.; Ikeda, Y.; Sciarretta, S.; Liu, T.; Li, H.; et al. An alternative mitophagy pathway mediated by Rab9 protects the heart against ischemia. J. Clin. Investig. 2019, 129, 802-819. [CrossRef]

39. Tong, M.; Saito, T.; Zhai, P.; Oka, S.; Mizushima, W.; Nakamura, M.; Ikeda, S.; Shirakabe, A.; Sadoshima, J. Mitophagy Is Essential for Maintaining Cardiac Function During High Fat Diet-Induced Diabetic Cardiomyopathy. Circ. Res. 2019, 124, 1360-1371. [CrossRef]

40. Yamaguchi, O.; Murakawa, T.; Nishida, K.; Otsu, K. Receptor-mediated mitophagy. J. Mol. Cell. Cardiol. 2016, 95, 50-56. [CrossRef]

41. Zhang, W.; Chen, C.; Wang, J.; Liu, L.; He, Y.; Chen, Q. Mitophagy in Cardiomyocytes and in Platelets: A Major Mechanism of Cardioprotection Against Ischemia/Reperfusion Injury. Physiology 2018, 33, 86-98. [CrossRef] [PubMed]

42. $\mathrm{Wu}, \mathrm{H}$.; Chen, Q. Hypoxia Activation of Mitophagy and Its Role in Disease Pathogenesis. Antioxid. Redox Signal. 2015, 22, 1032-1046. [CrossRef]

43. Davis, C.O.; Marsh-Armstrong, N. Discovery and implications of transcellular mitophagy. Autophagy 2014, 10, 2383-2384 [CrossRef] [PubMed]

44. Jackson, J.G.; Robinson, M.B. Regulation of mitochondrial dynamics in astrocytes: Mechanisms, consequences, and unknowns. Glia 2018, 66, 1213-1234. [CrossRef]

45. Morales, I.; Sanchez, A.; Puertas-Avendaño, R.; Rodriguez-Sabate, C.; Perez-Barreto, A.; Rodriguez, M. Neuroglial transmitophagy and Parkinson's disease. Glia 2020, 68, 2277-2299. [CrossRef]

46. Narendra, D.; Tanaka, A.; Suen, D.-F.; Youle, R.J. Parkin is recruited selectively to impaired mitochondria and promotes their autophagy. J. Cell Biol. 2008, 183, 795-803. [CrossRef] [PubMed]

47. Matsuda, N.; Sato, S.; Shiba, K.; Okatsu, K.; Saisho, K.; Gautier, C.A.; Sou, Y.; Saiki, S.; Kawajiri, S.; Sato, F.; et al. PINK1 stabilized by mitochondrial depolarization recruits Parkin to damaged mitochondria and activates latent Parkin for mitophagy. J. Cell Biol. 2010, 189, 211-221. [CrossRef] [PubMed]

48. Narendra, D.P.; Jin, S.M.; Tanaka, A.; Suen, D.-F.; Gautier, C.A.; Shen, J.; Cookson, M.R.; Youle, R.J. PINK1 Is Selectively Stabilized on Impaired Mitochondria to Activate Parkin. PLoS Biol. 2010, 8, e1000298. [CrossRef]

49. Kitada, T.; Asakawa, S.; Hattori, N.; Matsumine, H.; Yamamura, Y.; Minoshima, S.; Yokochi, M.; Mizuno, Y.; Shimizu, N. Mutations in the parkin gene cause autosomal recessive juvenile parkinsonism. Nature 1998, 392, 605-608. [CrossRef]

50. Valente, E.M.; Abou-Sleiman, P.M.; Caputo, V.; Muqit, M.M.K.; Harvey, K.; Gispert, S.; Ali, Z.; Del Turco, D.; Bentivoglio, A.R.; Healy, D.G.; et al. Hereditary Early-Onset Parkinson's Disease Caused by Mutations in PINK1. Science 2004, 304, 1158-1160. [CrossRef] [PubMed]

51. Perez, F.A.; Palmiter, R.D. Parkin-deficient mice are not a robust model of parkinsonism. Proc. Natl. Acad. Sci. USA 2005, 102, 2174-2179. [CrossRef]

52. Gispert, S.; Ricciardi, F.; Kurz, A.; Azizov, M.; Hoepken, H.-H.; Becker, D.; Voos, W.; Leuner, K.; Müller, W.E.; Kudin, A.P.; et al Parkinson Phenotype in Aged PINK1-Deficient Mice Is Accompanied by Progressive Mitochondrial Dysfunction in Absence of Neurodegeneration. PLoS ONE 2009, 4, e5777. [CrossRef]

53. Villa, E.; Marchetti, S.; Ricci, J.-E. No Parkin Zone: Mitophagy without Parkin. Trends Cell Biol. 2018, 28, 882-895. [CrossRef] [PubMed] 
54. Onishi, M.; Yamano, K.; Sato, M.; Matsuda, N.; Okamoto, K. Molecular mechanisms and physiological functions of mitophagy. EMBO J. 2021, 40, e104705. [CrossRef]

55. Liu, J.; Liu, W.; Li, R.; Yang, H. Mitophagy in Parkinson's Disease: From Pathogenesis to Treatment. Cells 2019, 8, 712. [CrossRef] [PubMed]

56. Doblado, L.; Lueck, C.; Rey, C.; Samhan-Arias, A.K.; Prieto, I.; Stacchiotti, A.; Monsalve, M. Mitophagy in Human Diseases. Int. J. Mol. Sci. 2021, 22, 3903. [CrossRef]

57. Herzig, S.; Shaw, R.J. AMPK: Guardian of metabolism and mitochondrial homeostasis. Nat. Rev. Mol. Cell Biol. 2018, 19, 121-135. [CrossRef] [PubMed]

58. Ke, P.-Y. Mitophagy in the Pathogenesis of Liver Diseases. Cells 2020, 9, 831. [CrossRef]

59. Liu, L.; Liao, X.; Wu, H.; Li, Y.; Zhu, Y.; Chen, Q. Mitophagy and Its Contribution to Metabolic and Aging-Associated Disorders. Antioxid. Redox Signal. 2020, 32, 906-927. [CrossRef]

60. Macleod, K.F. Mitophagy and Mitochondrial Dysfunction in Cancer. Annu. Rev. Cancer Biol. 2020, 4, 41-60. [CrossRef]

61. Morciano, G.; Patergnani, S.; Bonora, M.; Pedriali, G.; Tarocco, A.; Bouhamida, E.; Marchi, S.; Ancora, G.; Anania, G.; Wieckowski, M.R.; et al. Mitophagy in Cardiovascular Diseases. J. Clin. Med. 2020, 9, 892. [CrossRef]

62. Xu, Y.; Tang, Y.; Lu, J.; Zhang, W.; Zhu, Y.; Zhang, S.; Ma, G.; Jiang, P.; Zhang, W. PINK1-mediated mitophagy protects against hepatic ischemia/reperfusion injury by restraining NLRP3 inflammasome activation. Free Radic. Biol. Med. 2020, 160, 871-886. [CrossRef] [PubMed]

63. Georgakopoulos, N.D.; Wells, G.; Campanella, M. The pharmacological regulation of cellular mitophagy. Nat. Chem. Biol. 2017, 13, 136-146. [CrossRef] [PubMed]

64. Palikaras, K.; Princz, A.; Tavernarakis, N. Mitophagy Modulators. In Encyclopedia of Biomedical Gerontology; Reference Module in Biomedical Sciences; Academic Press: Cambridge, MA, USA, 2018.

65. Killackey, S.A.; Philpott, D.J.; Girardin, S.E. Mitophagy pathways in health and disease. J. Cell Biol. 2020, 219 , e202004029. [CrossRef] [PubMed]

66. Youle, R.J.; Narendra, D.P. Mechanisms of mitophagy. Nat. Rev. Mol. Cell Biol. 2011, 12, 9-14. [CrossRef]

67. Shimura, H.; Hattori, N.; Kubo, S.; Mizuno, Y.; Asakawa, S.; Minoshima, S.; Shimizu, N.; Iwai, K.; Chiba, T.; Tanaka, K.; et al. Familial Parkinson disease gene product, parkin, is a ubiquitin-protein ligase. Nat. Genet. 2000, 25, 302-305. [CrossRef]

68. Vives-Bauza, C.; Zhou, C.; Huang, Y.; Cui, M.; de Vries, R.L.A.; Kim, J.; May, J.; Tocilescu, M.A.; Liu, W.; Ko, H.S.; et al. PINK1-dependent recruitment of Parkin to mitochondria in mitophagy. Proc. Natl. Acad. Sci. USA 2010, 107, 378-383. [CrossRef]

69. Wong, Y.C.; Holzbaur, E.L.F. Optineurin is an autophagy receptor for damaged mitochondria in parkin-mediated mitophagy that is disrupted by an ALS-linked mutation. Proc. Natl. Acad. Sci. USA 2014, 111, E4439-E4448. [CrossRef]

70. Wong, Y.C.; Holzbaur, E.L.F. Temporal dynamics of PARK2/parkin and OPTN/optineurin recruitment during the mitophagy of damaged mitochondria. Autophagy 2015, 11, 422-424. [CrossRef]

71. Vargas, J.N.S.; Wang, C.; Bunker, E.; Hao, L.; Maric, D.; Schiavo, G.; Randow, F.; Youle, R.J. Spatiotemporal Control of ULK1 Activation by NDP52 and TBK1 during Selective Autophagy. Mol. Cell 2019, 74, 347-362.e6. [CrossRef]

72. Yamano, K.; Kikuchi, R.; Kojima, W.; Hayashida, R.; Koyano, F.; Kawawaki, J.; Shoda, T.; Demizu, Y.; Naito, M.; Tanaka, K.; et al. Critical role of mitochondrial ubiquitination and the OPTN-ATG9A axis in mitophagy. J. Cell Biol. 2020,219, e201912144. [CrossRef]

73. Riley, B.E.; Lougheed, J.C.; Callaway, K.; Velasquez, M.; Brecht, E.; Nguyen, L.; Shaler, T.; Walker, D.; Yang, Y.; Regnstrom, K.; et al. Structure and function of Parkin E3 ubiquitin ligase reveals aspects of RING and HECT ligases. Nat. Commun. $2013,4,1982$. [CrossRef]

74. Trempe, J.-F.; Sauvé, V.; Grenier, K.; Seirafi, M.; Tang, M.Y.; Ménade, M.; Al-Abdul-Wahid, S.; Krett, J.; Wong, K.; Kozlov, G.; et al. Structure of Parkin Reveals Mechanisms for Ubiquitin Ligase Activation. Science 2013, 340, 1451-1455. [CrossRef]

75. Wauer, T.; Komander, D. Structure of the human Parkin ligase domain in an autoinhibited state. EMBO J. 2013, 32, 2099-2112. [CrossRef]

76. Kumar, A.; Aguirre, J.D.; Condos, T.E.; Martinez-Torres, R.J.; Chaugule, V.K.; Toth, R.; Sundaramoorthy, R.; Mercier, P.; Knebel, A.; Spratt, D.E.; et al. Disruption of the autoinhibited state primes the E3 ligase parkin for activation and catalysis. EMBO J. 2015, 34 2506-2521. [CrossRef]

77. Wenzel, D.M.; Klevit, R.E. Following Ariadne's thread: A new perspective on RBR ubiquitin ligases. BMC Biol. 2012, 10, 24. [CrossRef] [PubMed]

78. Berndsen, C.E.; Wolberger, C. New insights into ubiquitin E3 ligase mechanism. Nat. Struct. Mol. Biol. 2014, 21, 301-307. [CrossRef] [PubMed]

79. Gladkova, C.; Maslen, S.L.; Skehel, J.M.; Komander, D. Mechanism of parkin activation by PINK1. Nature 2018, 559, 410-414. [CrossRef] [PubMed]

80. Sauvé, V.; Sung, G.; Soya, N.; Kozlov, G.; Blaimschein, N.; Miotto, L.S.; Trempe, J.-F.; Lukacs, G.L.; Gehring, K. Mechanism of parkin activation by phosphorylation. Nat. Struct. Mol. Biol. 2018, 25, 623-630. [CrossRef]

81. Gundogdu, M.; Tadayon, R.; Salzano, G.; Shaw, G.S.; Walden, H. A mechanistic review of Parkin activation. Biochim. Biophys. Acta-Gen. Subj. 2021, 1865, 129894. [CrossRef] [PubMed]

82. Kane, L.A.; Lazarou, M.; Fogel, A.I.; Li, Y.; Yamano, K.; Sarraf, S.A.; Banerjee, S.; Youle, R.J. PINK1 phosphorylates ubiquitin to activate Parkin E3 ubiquitin ligase activity. J. Cell Biol. 2014, 205, 143-153. [CrossRef] [PubMed] 
83. Kazlauskaite, A.; Kondapalli, C.; Gourlay, R.; Campbell, D.G.; Ritorto, M.S.; Hofmann, K.; Alessi, D.R.; Knebel, A.; Trost, M.; Muqit, M.M.K. Parkin is activated by PINK1-dependent phosphorylation of ubiquitin at Ser65. Biochem. J. 2014, 460, 127-141. [CrossRef] [PubMed]

84. Koyano, F.; Okatsu, K.; Kosako, H.; Tamura, Y.; Go, E.; Kimura, M.; Kimura, Y.; Tsuchiya, H.; Yoshihara, H.; Hirokawa, T.; et al. Ubiquitin is phosphorylated by PINK1 to activate parkin. Nature 2014, 510, 162-166. [CrossRef]

85. Ordureau, A.; Sarraf, S.A.; Duda, D.M.; Heo, J.-M.; Jedrychowski, M.P.; Sviderskiy, V.O.; Olszewski, J.L.; Koerber, J.T.; Xie, T.; Beausoleil, S.A.; et al. Quantitative Proteomics Reveal a Feedforward Mechanism for Mitochondrial PARKIN Translocation and Ubiquitin Chain Synthesis. Mol. Cell 2014, 56, 360-375. [CrossRef]

86. Kazlauskaite, A.; Martínez-Torres, R.J.; Wilkie, S.; Kumar, A.; Peltier, J.; Gonzalez, A.; Johnson, C.; Zhang, J.; Hope, A.G.; Peggie, M.; et al. Binding to serine 65-phosphorylated ubiquitin primes Parkin for optimal PINK 1-dependent phosphorylation and activation. EMBO Rep. 2015, 16, 939-954. [CrossRef] [PubMed]

87. Sauvé, V.; Lilov, A.; Seirafi, M.; Vranas, M.; Rasool, S.; Kozlov, G.; Sprules, T.; Wang, J.; Trempe, J.; Gehring, K. A Ubl/ubiquitin switch in the activation of Parkin. EMBO J. 2015, 34, 2492-2505. [CrossRef]

88. Wauer, T.; Simicek, M.; Schubert, A.; Komander, D. Mechanism of phospho-ubiquitin-induced PARKIN activation. Nature 2015, 524, 370-374. [CrossRef]

89. Yamano, K.; Queliconi, B.B.; Koyano, F.; Saeki, Y.; Hirokawa, T.; Tanaka, K.; Matsuda, N. Site-specific Interaction Mapping of Phosphorylated Ubiquitin to Uncover Parkin Activation. J. Biol. Chem. 2015, 290, 25199-25211. [CrossRef]

90. Okatsu, K.; Koyano, F.; Kimura, M.; Kosako, H.; Saeki, Y.; Tanaka, K.; Matsuda, N. Phosphorylated ubiquitin chain is the genuine Parkin receptor. J. Cell Biol. 2015, 209, 111-128. [CrossRef]

91. Ordureau, A.; Heo, J.-M.; Duda, D.M.; Paulo, J.A.; Olszewski, J.L.; Yanishevski, D.; Rinehart, J.; Schulman, B.A.; Harper, J.W. Defining roles of PARKIN and ubiquitin phosphorylation by PINK1 in mitochondrial quality control using a ubiquitin replacement strategy. Proc. Natl. Acad. Sci. USA 2015, 112, 6637-6642. [CrossRef]

92. Cunningham, C.N.; Baughman, J.M.; Phu, L.; Tea, J.S.; Yu, C.; Coons, M.; Kirkpatrick, D.S.; Bingol, B.; Corn, J.E. USP30 and parkin homeostatically regulate atypical ubiquitin chains on mitochondria. Nat. Cell Biol. 2015, 17, 160-169. [CrossRef]

93. Sarraf, S.A.; Raman, M.; Guarani-Pereira, V.; Sowa, M.E.; Huttlin, E.L.; Gygi, S.P.; Harper, J.W. Landscape of the PARKINdependent ubiquitylome in response to mitochondrial depolarization. Nature 2013, 496, 372-376. [CrossRef] [PubMed]

94. Rose, C.M.; Isasa, M.; Ordureau, A.; Prado, M.A.; Beausoleil, S.A.; Jedrychowski, M.P.; Finley, D.J.; Harper, J.W.; Gygi, S.P. Highly Multiplexed Quantitative Mass Spectrometry Analysis of Ubiquitylomes. Cell Syst. 2016, 3, 395-403.e4. [CrossRef] [PubMed]

95. Ordureau, A.; Paulo, J.A.; Zhang, W.; Ahfeldt, T.; Zhang, J.; Cohn, E.F.; Hou, Z.; Heo, J.-M.; Rubin, L.L.; Sidhu, S.S.; et al. Dynamics of PARKIN-Dependent Mitochondrial Ubiquitylation in Induced Neurons and Model Systems Revealed by Digital Snapshot Proteomics. Mol. Cell 2018, 70, 211-227.e8. [CrossRef] [PubMed]

96. Bayne, A.N.; Trempe, J.-F. Mechanisms of PINK1, ubiquitin and Parkin interactions in mitochondrial quality control and beyond Cell. Mol. Life Sci. 2019, 76, 4589-4611. [CrossRef] [PubMed]

97. Shiba-Fukushima, K.; Arano, T.; Matsumoto, G.; Inoshita, T.; Yoshida, S.; Ishihama, Y.; Ryu, K.-Y.; Nukina, N.; Hattori, N.; Imai, Y. Phosphorylation of Mitochondrial Polyubiquitin by PINK1 Promotes Parkin Mitochondrial Tethering. PLoS Genet. 2014, 10, e1004861. [CrossRef]

98. Okatsu, K.; Kimura, M.; Oka, T.; Tanaka, K.; Matsuda, N. Unconventional PINK1 localization mechanism to the outer membrane of depolarized mitochondria drives Parkin recruitment. J. Cell Sci. 2015, 128, 964-978. [CrossRef]

99. Yamano, K.; Matsuda, N.; Tanaka, K. The ubiquitin signal and autophagy: An orchestrated dance leading to mitochondrial degradation. EMBO Rep. 2016, 17, 300-316. [CrossRef]

100. Matsuda, N.; Yamano, K. Two sides of a coin: Physiological significance and molecular mechanisms for damage-induced mitochondrial localization of PINK1 and Parkin. Neurosci. Res. 2020, 159, 16-24. [CrossRef]

101. Koyano, F.; Yamano, K.; Kosako, H.; Tanaka, K.; Matsuda, N. Parkin recruitment to impaired mitochondria for nonselective ubiquitylation is facilitated by MITOL. J. Biol. Chem. 2019, 294, 10300-10314. [CrossRef]

102. Wang, X.; Winter, D.; Ashrafi, G.; Schlehe, J.; Wong, Y.L.; Selkoe, D.; Rice, S.; Steen, J.; LaVoie, M.J.; Schwarz, T.L. PINK1 and Parkin Target Miro for Phosphorylation and Degradation to Arrest Mitochondrial Motility. Cell 2011, 147, 893-906. [CrossRef] [PubMed]

103. Chen, Y.; Dorn, G.W. PINK1-Phosphorylated Mitofusin 2 Is a Parkin Receptor for Culling Damaged Mitochondria. Science 2013, 340, 471-475. [CrossRef] [PubMed]

104. de Brito, O.M.; Scorrano, L. Mitofusin 2 tethers endoplasmic reticulum to mitochondria. Nature 2008, 456, 605-610. [CrossRef] [PubMed]

105. Rocha, A.G.; Franco, A.; Krezel, A.M.; Rumsey, J.M.; Alberti, J.M.; Knight, W.C.; Biris, N.; Zacharioudakis, E.; Janetka, J.W.; Baloh, R.H.; et al. MFN2 agonists reverse mitochondrial defects in preclinical models of Charcot-Marie-Tooth disease type 2A. Science 2018, 360, 336-341. [CrossRef]

106. Gong, G.; Song, M.; Csordas, G.; Kelly, D.P.; Matkovich, S.J.; Dorn, G.W. Parkin-mediated mitophagy directs perinatal cardiac metabolic maturation in mice. Science 2015, 350, aad2459. [CrossRef] [PubMed]

107. Poole, A.C.; Thomas, R.E.; Yu, S.; Vincow, E.S.; Pallanck, L. The Mitochondrial Fusion-Promoting Factor Mitofusin Is a Substrate of the PINK1/Parkin Pathway. PLoS ONE 2010, 5, e10054. [CrossRef] 
108. Gegg, M.E.; Cooper, J.M.; Chau, K.-Y.; Rojo, M.; Schapira, A.H.V.; Taanman, J.-W. Mitofusin 1 and mitofusin 2 are ubiquitinated in a PINK1/parkin-dependent manner upon induction of mitophagy. Hum. Mol. Genet. 2010, 19, 4861-4870. [CrossRef]

109. Tanaka, A.; Cleland, M.M.; Xu, S.; Narendra, D.P.; Suen, D.-F.; Karbowski, M.; Youle, R.J. Proteasome and p97 mediate mitophagy and degradation of mitofusins induced by Parkin. J. Cell Biol. 2010, 191, 1367-1380. [CrossRef]

110. McLelland, G.-L.; Goiran, T.; Yi, W.; Dorval, G.; Chen, C.X.; Lauinger, N.D.; Krahn, A.I.; Valimehr, S.; Rakovic, A.; Rouiller, I.; et al. Mfn2 ubiquitination by PINK1/parkin gates the p97-dependent release of ER from mitochondria to drive mitophagy. eLife 2018, 7, e32866. [CrossRef]

111. Gelmetti, V.; De Rosa, P.; Torosantucci, L.; Marini, E.S.; Romagnoli, A.; Di Rienzo, M.; Arena, G.; Vignone, D.; Fimia, G.M.; Valente, E.M. PINK1 and BECN1 relocalize at mitochondria-associated membranes during mitophagy and promote ER-mitochondria tethering and autophagosome formation. Autophagy 2017, 13, 654-669. [CrossRef]

112. Schwarz, T.L. Mitochondrial Trafficking in Neurons. Cold Spring Harb. Perspect. Biol. 2013, 5, a011304. [CrossRef] [PubMed]

113. van der Merwe, C.; Jalali Sefid Dashti, Z.; Christoffels, A.; Loos, B.; Bardien, S. Evidence for a common biological pathway linking three Parkinson's disease-causing genes: Parkin, PINK1 and DJ-1. Eur. J. Neurosci. 2015, 41, 1113-1125. [CrossRef] [PubMed]

114. Shlevkov, E.; Kramer, T.; Schapansky, J.; LaVoie, M.J.; Schwarz, T.L. Miro phosphorylation sites regulate Parkin recruitment and mitochondrial motility. Proc. Natl. Acad. Sci. USA 2016, 113, E6097-E6106. [CrossRef] [PubMed]

115. Bingol, B.; Tea, J.S.; Phu, L.; Reichelt, M.; Bakalarski, C.E.; Song, Q.; Foreman, O.; Kirkpatrick, D.S.; Sheng, M. The mitochondrial deubiquitinase USP30 opposes parkin-mediated mitophagy. Nature 2014, 510, 370-375. [CrossRef]

116. Cornelissen, T.; Haddad, D.; Wauters, F.; Van Humbeeck, C.; Mandemakers, W.; Koentjoro, B.; Sue, C.; Gevaert, K.; De Strooper, B.; Verstreken, P.; et al. The deubiquitinase USP15 antagonizes Parkin-mediated mitochondrial ubiquitination and mitophagy. Hum. Mol. Genet. 2014, 23, 5227-5242. [CrossRef]

117. Liang, J.; Martinez, A.; Lane, J.D.; Mayor, U.; Clague, M.J.; Urbé, S. USP 30 deubiquitylates mitochondrial Parkin substrates and restricts apoptotic cell death. EMBO Rep. 2015, 16, 618-627. [CrossRef]

118. Niu, K.; Fang, H.; Chen, Z.; Zhu, Y.; Tan, Q.; Wei, D.; Li, Y.; Balajee, A.S.; Zhao, Y. USP33 deubiquitinates PRKN/parkin and antagonizes its role in mitophagy. Autophagy 2020, 16, 724-734. [CrossRef]

119. Gersch, M.; Gladkova, C.; Schubert, A.F.; Michel, M.A.; Maslen, S.; Komander, D. Mechanism and regulation of the Lys6-selective deubiquitinase USP30. Nat. Struct. Mol. Biol. 2017, 24, 920-930. [CrossRef]

120. Sato, Y.; Okatsu, K.; Saeki, Y.; Yamano, K.; Matsuda, N.; Kaiho, A.; Yamagata, A.; Goto-Ito, S.; Ishikawa, M.; Hashimoto, Y.; et al Structural basis for specific cleavage of Lys6-linked polyubiquitin chains by USP30. Nat. Struct. Mol. Biol. 2017, 24, 911-919. [CrossRef]

121. Phu, L.; Rose, C.M.; Tea, J.S.; Wall, C.E.; Verschueren, E.; Cheung, T.K.; Kirkpatrick, D.S.; Bingol, B. Dynamic Regulation of Mitochondrial Import by the Ubiquitin System. Mol. Cell 2020, 77, 1107-1123.e10. [CrossRef]

122. Marcassa, E.; Kallinos, A.; Jardine, J.; Rusilowicz-Jones, E.V.; Martinez, A.; Kuehl, S.; Islinger, M.; Clague, M.J.; Urbé, S. Dual role of USP 30 in controlling basal pexophagy and mitophagy. EMBO Rep. 2018, 19, e45595. [CrossRef] [PubMed]

123. Rusilowicz-Jones, E.V.; Jardine, J.; Kallinos, A.; Pinto-Fernandez, A.; Guenther, F.; Giurrandino, M.; Barone, F.G.; McCarron, K.; Burke, C.J.; Murad, A.; et al. USP30 sets a trigger threshold for PINK1-PARKIN amplification of mitochondrial ubiquitylation. Life Sci. Alliance 2020, 3, e202000768. [CrossRef] [PubMed]

124. Durcan, T.M.; Tang, M.Y.; Pérusse, J.R.; Dashti, E.A.; Aguileta, M.A.; McLelland, G.; Gros, P.; Shaler, T.A.; Faubert, D.; Coulombe, B.; et al. USP8 regulates mitophagy by removing K6-linked ubiquitin conjugates from parkin. EMBO J. 2014, 33, 2473-2491. [CrossRef] [PubMed]

125. Ordureau, A.; Paulo, J.A.; Zhang, J.; An, H.; Swatek, K.N.; Cannon, J.R.; Wan, Q.; Komander, D.; Harper, J.W. Global Landscape and Dynamics of Parkin and USP30-Dependent Ubiquitylomes in iNeurons during Mitophagic Signaling. Mol. Cell 2020, 77, 1124-1142.e10. [CrossRef] [PubMed]

126. Wauer, T.; Swatek, K.N.; Wagstaff, J.L.; Gladkova, C.; Pruneda, J.N.; Michel, M.A.; Gersch, M.; Johnson, C.M.; Freund, S.M.; Komander, D. Ubiquitin Ser65 phosphorylation affects ubiquitin structure, chain assembly and hydrolysis. EMBO J. 2015, 34, 307-325. [CrossRef]

127. Wang, Y.; Serricchio, M.; Jauregui, M.; Shanbhag, R.; Stoltz, T.; Di Paolo, C.T.; Kim, P.K.; McQuibban, G.A. Deubiquitinating enzymes regulate PARK2-mediated mitophagy. Autophagy 2015, 11, 595-606. [CrossRef]

128. Wang, L.; Wang, J.; Tang, Y.; Shen, H.-M. PTEN-L puts a brake on mitophagy. Autophagy 2018, 14, 2023-2025. [CrossRef]

129. Wang, L.; Cho, Y.-L.; Tang, Y.; Wang, J.; Park, J.-E.; Wu, Y.; Wang, C.; Tong, Y.; Chawla, R.; Zhang, J.; et al. PTEN-L is a novel protein phosphatase for ubiquitin dephosphorylation to inhibit PINK1-Parkin-mediated mitophagy. Cell Res. 2018, 28, 787-802. [CrossRef]

130. Shiba-Fukushima, K.; Imai, Y.; Yoshida, S.; Ishihama, Y.; Kanao, T.; Sato, S.; Hattori, N. PINK1-mediated phosphorylation of the Parkin ubiquitin-like domain primes mitochondrial translocation of Parkin and regulates mitophagy. Sci. Rep. 2012, 2, 1002. [CrossRef]

131. Zhuang, N.; Li, L.; Chen, S.; Wang, T. PINK1-dependent phosphorylation of PINK1 and Parkin is essential for mitochondrial quality control. Cell Death Dis. 2016, 7, e2501. [CrossRef]

132. Tang, M.Y.; Vranas, M.; Krahn, A.I.; Pundlik, S.; Trempe, J.-F.; Fon, E.A. Structure-guided mutagenesis reveals a hierarchical mechanism of Parkin activation. Nat. Commun. 2017, 8, 14697. [CrossRef] 
133. Sauvé, V.; Sung, G.; MacDougall, E.; Kozlov, G.; Saran, A.; Fakih, R.; Fon, E.; Gehring, K. Structural basis for feedforward control in the PINK1/Parkin pathway. bioRxiv 2021. [CrossRef]

134. Lee, S.B.; Kim, J.J.; Nam, H.-J.; Gao, B.; Yin, P.; Qin, B.; Yi, S.-Y.; Ham, H.; Evans, D.; Kim, S.-H.; et al. Parkin Regulates Mitosis and Genomic Stability through Cdc20/Cdh1. Mol. Cell 2015, 60, 21-34. [CrossRef] [PubMed]

135. Avraham, E.; Rott, R.; Liani, E.; Szargel, R.; Engelender, S. Phosphorylation of Parkin by the Cyclin-dependent Kinase 5 at the Linker Region Modulates Its Ubiquitin-Ligase Activity and Aggregation. J. Biol. Chem. 2007, 282, 12842-12850. [CrossRef] [PubMed]

136. Ko, H.S.; Lee, Y.; Shin, J.-H.; Karuppagounder, S.S.; Gadad, B.S.; Koleske, A.J.; Pletnikova, O.; Troncoso, J.C.; Dawson, V.L.; Dawson, T.M. Phosphorylation by the c-Abl protein tyrosine kinase inhibits parkin's ubiquitination and protective function. Proc. Natl. Acad. Sci. USA 2010, 107, 16691-16696. [CrossRef]

137. Imam, S.Z.; Zhou, Q.; Yamamoto, A.; Valente, A.J.; Ali, S.F.; Bains, M.; Roberts, J.L.; Kahle, P.J.; Clark, R.A.; Li, S. Novel Regulation of Parkin Function through c-Abl-Mediated Tyrosine Phosphorylation: Implications for Parkinson's Disease. J. Neurosci. 2011, 31, 157-163. [CrossRef]

138. Kato, H.; Lu, Q.; Rapaport, D.; Kozjak-Pavlovic, V. Tom70 Is Essential for PINK1 Import into Mitochondria. PLoS ONE 2013, 8 , e58435. [CrossRef]

139. Sekine, S.; Wang, C.; Sideris, D.P.; Bunker, E.; Zhang, Z.; Youle, R.J. Reciprocal Roles of Tom7 and OMA1 during Mitochondrial Import and Activation of PINK1. Mol. Cell 2019, 73, 1028-1043.e5. [CrossRef] [PubMed]

140. Deas, E.; Plun-Favreau, H.; Gandhi, S.; Desmond, H.; Kjaer, S.; Loh, S.H.Y.; Renton, A.E.M.; Harvey, R.J.; Whitworth, A.J.; Martins, L.M.; et al. PINK1 cleavage at position A103 by the mitochondrial protease PARL. Hum. Mol. Genet. 2011, 20, 867-879. [CrossRef]

141. Greene, A.W.; Grenier, K.; Aguileta, M.A.; Muise, S.; Farazifard, R.; Haque, M.E.; McBride, H.M.; Park, D.S.; Fon, E.A. Mitochondrial processing peptidase regulates PINK1 processing, import and Parkin recruitment. EMBO Rep. 2012, 13, 378-385. [CrossRef]

142. Jin, S.M.; Lazarou, M.; Wang, C.; Kane, L.A.; Narendra, D.P.; Youle, R.J. Mitochondrial membrane potential regulates PINK1 import and proteolytic destabilization by PARL. J. Cell Biol. 2010, 191, 933-942. [CrossRef]

143. Meissner, C.; Lorenz, H.; Weihofen, A.; Selkoe, D.J.; Lemberg, M.K. The mitochondrial intramembrane protease PARL cleaves human Pink1 to regulate Pink1 trafficking. J. Neurochem. 2011, 117, 856-867. [CrossRef] [PubMed]

144. Sekine, S.; Youle, R.J. PINK1 import regulation; a fine system to convey mitochondrial stress to the cytosol. BMC Biol. 2018, 16, 2. [CrossRef] [PubMed]

145. Yamano, K.; Youle, R.J. PINK1 is degraded through the N-end rule pathway. Autophagy 2013, 9, 1758-1769. [CrossRef] [PubMed]

146. Liu, Y.; Guardia-Laguarta, C.; Yin, J.; Erdjument-Bromage, H.; Martin, B.; James, M.; Jiang, X.; Przedborski, S. The Ubiquitination of PINK1 Is Restricted to Its Mature 52-kDa Form. Cell Rep. 2017, 20, 30-39. [CrossRef] [PubMed]

147. Okatsu, K.; Oka, T.; Iguchi, M.; Imamura, K.; Kosako, H.; Tani, N.; Kimura, M.; Go, E.; Koyano, F.; Funayama, M.; et al. PINK1 autophosphorylation upon membrane potential dissipation is essential for Parkin recruitment to damaged mitochondria. Nat. Commun. 2012, 3, 1016. [CrossRef]

148. Okatsu, K.; Uno, M.; Koyano, F.; Go, E.; Kimura, M.; Oka, T.; Tanaka, K.; Matsuda, N. A Dimeric PINK1-containing Complex on Depolarized Mitochondria Stimulates Parkin Recruitment. J. Biol. Chem. 2013, 288, 36372-36384. [CrossRef]

149. Rasool, S.; Soya, N.; Truong, L.; Croteau, N.; Lukacs, G.L.; Trempe, J. PINK 1 autophosphorylation is required for ubiquitin recognition. EMBO Rep. 2018, 19, e44981. [CrossRef]

150. Morais, V.A.; Haddad, D.; Craessaerts, K.; De Bock, P.-J.; Swerts, J.; Vilain, S.; Aerts, L.; Overbergh, L.; Grünewald, A.; Seibler, P.; et al. PINK1 Loss-of-Function Mutations Affect Mitochondrial Complex I Activity via NdufA10 Ubiquinone Uncoupling. Science 2014, 344, 203-207. [CrossRef]

151. Tsai, P.-I.; Lin, C.-H.; Hsieh, C.-H.; Papakyrikos, A.M.; Kim, M.J.; Napolioni, V.; Schoor, C.; Couthouis, J.; Wu, R.-M.; Wszolek, Z.K.; et al. PINK1 Phosphorylates MIC60/Mitofilin to Control Structural Plasticity of Mitochondrial Crista Junctions. Mol. Cell 2018, 69, 744-756.e6. [CrossRef]

152. Regula, K.M.; Ens, K.; Kirshenbaum, L.A. Inducible Expression of BNIP3 Provokes Mitochondrial Defects and Hypoxia-Mediated Cell Death of Ventricular Myocytes. Circ. Res. 2002, 91, 226-231. [CrossRef]

153. Diwan, A.; Krenz, M.; Syed, F.M.; Wansapura, J.; Ren, X.; Koesters, A.G.; Li, H.; Kirshenbaum, L.A.; Hahn, H.S.; Robbins, J.; et al Inhibition of ischemic cardiomyocyte apoptosis through targeted ablation of Bnip3 restrains postinfarction remodeling in mice. $J$. Clin. Investig. 2007, 117, 2825-2833. [CrossRef] [PubMed]

154. Diwan, A.; Koesters, A.G.; Odley, A.M.; Pushkaran, S.; Baines, C.P.; Spike, B.T.; Daria, D.; Jegga, A.G.; Geiger, H.; Aronow, B.J.; et al. Unrestrained erythroblast development in Nix-/- mice reveals a mechanism for apoptotic modulation of erythropoiesis. Proc. Natl. Acad. Sci. USA 2007, 104, 6794-6799. [CrossRef] [PubMed]

155. Diwan, A.; Matkovich, S.J.; Yuan, Q.; Zhao, W.; Yatani, A.; Brown, J.H.; Molkentin, J.D.; Kranias, E.G.; Dorn, G.W. Endoplasmic reticulum-mitochondria crosstalk in NIX-mediated murine cell death. J. Clin. Investig. 2008, 119, 203-212. [CrossRef] [PubMed]

156. Zhang, H.; Bosch-Marce, M.; Shimoda, L.A.; Tan, Y.S.; Baek, J.H.; Wesley, J.B.; Gonzalez, F.J.; Semenza, G.L. Mitochondrial Autophagy Is an HIF-1-dependent Adaptive Metabolic Response to Hypoxia. J. Biol. Chem. 2008, 283, 10892-10903. [CrossRef]

157. Hanna, R.A.; Quinsay, M.N.; Orogo, A.M.; Giang, K.; Rikka, S.; Gustafsson, Å.B. Microtubule-associated Protein 1 Light Chain 3 (LC3) Interacts with Bnip3 Protein to Selectively Remove Endoplasmic Reticulum and Mitochondria via Autophagy. J. Biol. Chem. 2012, 287, 19094-19104. [CrossRef] 
158. Yuan, Y.; Zheng, Y.; Zhang, X.; Chen, Y.; Wu, X.; Wu, J.; Shen, Z.; Jiang, L.; Wang, L.; Yang, W.; et al. BNIP3L/NIX-mediated mitophagy protects against ischemic brain injury independent of PARK2. Autophagy 2017, 13, 1754-1766. [CrossRef]

159. Zhu, Y.; Massen, S.; Terenzio, M.; Lang, V.; Chen-Lindner, S.; Eils, R.; Novak, I.; Dikic, I.; Hamacher-Brady, A.; Brady, N.R Modulation of Serines 17 and 24 in the LC3-interacting Region of Bnip3 Determines Pro-survival Mitophagy versus Apoptosis. J. Biol. Chem. 2013, 288, 1099-1113. [CrossRef] [PubMed]

160. da Silva Rosa, S.C.; Martens, M.D.; Field, J.T.; Nguyen, L.; Kereliuk, S.M.; Hai, Y.; Chapman, D.; Diehl-Jones, W.; Aliani, M.; West, A.R.; et al. BNIP3L/Nix-induced mitochondrial fission, mitophagy, and impaired myocyte glucose uptake are abrogated by PRKA/PKA phosphorylation. Autophagy 2021, 17, 2257-2272. [CrossRef]

161. Schweers, R.L.; Zhang, J.; Randall, M.S.; Loyd, M.R.; Li, W.; Dorsey, F.C.; Kundu, M.; Opferman, J.T.; Cleveland, J.L.; Miller, J.L.; et al. NIX is required for programmed mitochondrial clearance during reticulocyte maturation. Proc. Natl. Acad. Sci. USA 2007, 104, 19500-19505. [CrossRef]

162. Novak, I.; Kirkin, V.; McEwan, D.G.; Zhang, J.; Wild, P.; Rozenknop, A.; Rogov, V.; Löhr, F.; Popovic, D.; Occhipinti, A.; et al. Nix is a selective autophagy receptor for mitochondrial clearance. EMBO Rep. 2010, 11, 45-51. [CrossRef]

163. Rogov, V.V.; Suzuki, H.; Marinković, M.; Lang, V.; Kato, R.; Kawasaki, M.; Buljubašić, M.; Šprung, M.; Rogova, N.; Wakatsuki, S.; et al. Phosphorylation of the mitochondrial autophagy receptor Nix enhances its interaction with LC3 proteins. Sci. Rep. 2017, 7, 1131. [CrossRef] [PubMed]

164. Marinković, M.; Šprung, M.; Novak, I. Dimerization of mitophagy receptor BNIP3L/NIX is essential for recruitment of autophagic machinery. Autophagy 2021, 17, 1232-1243. [CrossRef] [PubMed]

165. Poole, L.P.; Bock-Hughes, A.; Berardi, D.E.; Macleod, K.F. ULK1 promotes mitophagy via phosphorylation and stabilization of BNIP3. Sci. Rep. 2021, 11, 20526. [CrossRef]

166. Lee, Y.; Lee, H.-Y.; Hanna, R.A.; Gustafsson, Å.B. Mitochondrial autophagy by Bnip3 involves Drp1-mediated mitochondrial fission and recruitment of Parkin in cardiac myocytes. Am. J. Physiol. Circ. Physiol. 2011, 301, H1924-H1931. [CrossRef] [PubMed]

167. Zhang, T.; Xue, L.; Li, L.; Tang, C.; Wan, Z.; Wang, R.; Tan, J.; Tan, Y.; Han, H.; Tian, R.; et al. BNIP3 Protein Suppresses PINK1 Kinase Proteolytic Cleavage to Promote Mitophagy. J. Biol. Chem. 2016, 291, 21616-21629. [CrossRef]

168. Gao, F.; Chen, D.; Si, J.; Hu, Q.; Qin, Z.; Fang, M.; Wang, G. The mitochondrial protein BNIP3L is the substrate of PARK2 and mediates mitophagy in PINK1/PARK2 pathway. Hum. Mol. Genet. 2015, 24, 2528-2538. [CrossRef]

169. Ding, W.-X.; Ni, H.-M.; Li, M.; Liao, Y.; Chen, X.; Stolz, D.B.; Dorn, G.W.; Yin, X.-M. Nix Is Critical to Two Distinct Phases of Mitophagy, Reactive Oxygen Species-mediated Autophagy Induction and Parkin-Ubiquitin-p62-mediated Mitochondrial Priming J. Biol. Chem. 2010, 285, 27879-27890. [CrossRef]

170. Liu, L.; Feng, D.; Chen, G.; Chen, M.; Zheng, Q.; Song, P.; Ma, Q.; Zhu, C.; Wang, R.; Qi, W.; et al. Mitochondrial outer-membrane protein FUNDC1 mediates hypoxia-induced mitophagy in mammalian cells. Nat. Cell Biol. 2012, 14, 177-185. [CrossRef]

171. Chen, Z.; Liu, L.; Cheng, Q.; Li, Y.; Wu, H.; Zhang, W.; Wang, Y.; Sehgal, S.A.; Siraj, S.; Wang, X.; et al. Mitochondrial E3 ligase MARCH5 regulates FUNDC 1 to fine-tune hypoxic mitophagy. EMBO Rep. 2017, 18, 495-509. [CrossRef]

172. Chen, G.; Han, Z.; Feng, D.; Chen, Y.; Chen, L.; Wu, H.; Huang, L.; Zhou, C.; Cai, X.; Fu, C.; et al. A Regulatory Signaling Loop Comprising the PGAM5 Phosphatase and CK2 Controls Receptor-Mediated Mitophagy. Mol. Cell 2014, 54, 362-377. [CrossRef]

173. Wu, H.; Xue, D.; Chen, G.; Han, Z.; Huang, L.; Zhu, C.; Wang, X.; Jin, H.; Wang, J.; Zhu, Y.; et al. The BCL2L1 and PGAM5 axis defines hypoxia-induced receptor-mediated mitophagy. Autophagy 2014, 10, 1712-1725. [CrossRef] [PubMed]

174. Wu, W.; Tian, W.; Hu, Z.; Chen, G.; Huang, L.; Li, W.; Zhang, X.; Xue, P.; Zhou, C.; Liu, L.; et al. ULK1 translocates to mitochondria and phosphorylates FUNDC1 to regulate mitophagy. EMBO Rep. 2014, 15, 566-575. [CrossRef] [PubMed]

175. Lampert, M.A.; Orogo, A.M.; Najor, R.H.; Hammerling, B.C.; Leon, L.J.; Wang, B.J.; Kim, T.; Sussman, M.A.; Gustafsson, Å.B BNIP3L/NIX and FUNDC1-mediated mitophagy is required for mitochondrial network remodeling during cardiac progenitor cell differentiation. Autophagy 2019, 15, 1182-1198. [CrossRef] [PubMed]

176. Murakawa, T.; Yamaguchi, O.; Hashimoto, A.; Hikoso, S.; Takeda, T.; Oka, T.; Yasui, H.; Ueda, H.; Akazawa, Y.; Nakayama, H.; et al. Bcl-2-like protein 13 is a mammalian Atg32 homologue that mediates mitophagy and mitochondrial fragmentation. Nat. Commun. 2015, 6, 7527. [CrossRef]

177. Murakawa, T.; Okamoto, K.; Omiya, S.; Taneike, M.; Yamaguchi, O.; Otsu, K. A Mammalian Mitophagy Receptor, Bcl2-L-13, Recruits the ULK1 Complex to Induce Mitophagy. Cell Rep. 2019, 26, 338-345.e6. [CrossRef]

178. Bhujabal, Z.; Birgisdottir, Å.B.; Sjøttem, E.; Brenne, H.B.; Øvervatn, A.; Habisov, S.; Kirkin, V.; Lamark, T.; Johansen, T. FKBP8 recruits LC3A to mediate Parkin-independent mitophagy. EMBO Rep. 2017, 18, 947-961. [CrossRef]

179. Strappazzon, F.; Nazio, F.; Corrado, M.; Cianfanelli, V.; Romagnoli, A.; Fimia, G.M.; Campello, S.; Nardacci, R.; Piacentini, M.; Campanella, M.; et al. AMBRA1 is able to induce mitophagy via LC3 binding, regardless of PARKIN and p62/SQSTM1. Cell Death Differ. 2015, 22, 419-432. [CrossRef]

180. Van Humbeeck, C.; Cornelissen, T.; Hofkens, H.; Mandemakers, W.; Gevaert, K.; De Strooper, B.; Vandenberghe, W. Parkin Interacts with Ambra1 to Induce Mitophagy. J. Neurosci. 2011, 31, 10249-10261. [CrossRef]

181. Di Rita, A.; D'Acunzo, P.; Simula, L.; Campello, S.; Strappazzon, F.; Cecconi, F. AMBRA1-Mediated Mitophagy Counteracts Oxidative Stress and Apoptosis Induced by Neurotoxicity in Human Neuroblastoma SH-SY5Y Cells. Front. Cell. Neurosci. 2018, 12, 92. [CrossRef] 
182. Chu, C.T.; Ji, J.; Dagda, R.K.; Jiang, J.F.; Tyurina, Y.Y.; Kapralov, A.A.; Tyurin, V.A.; Yanamala, N.; Shrivastava, I.H.; Mohammadyani, D.; et al. Cardiolipin externalization to the outer mitochondrial membrane acts as an elimination signal for mitophagy in neuronal cells. Nat. Cell Biol. 2013, 15, 1197-1205. [CrossRef]

183. Li, X.-X.; Tsoi, B.; Li, Y.-F.; Kurihara, H.; He, R.-R. Cardiolipin and Its Different Properties in Mitophagy and Apoptosis. J. Histochem. Cytochem. 2015, 63, 301-311. [CrossRef] [PubMed]

184. Fu, M.; St-Pierre, P.; Shankar, J.; Wang, P.T.C.; Joshi, B.; Nabi, I.R. Regulation of mitophagy by the Gp78 E3 ubiquitin ligase. Mol. Biol. Cell 2013, 24, 1153-1162. [CrossRef]

185. Ambivero, C.T.; Cilenti, L.; Main, S.; Zervos, A.S. Mulan E3 ubiquitin ligase interacts with multiple E2 conjugating enzymes and participates in mitophagy by recruiting GABARAP. Cell. Signal. 2014, 26, 2921-2929. [CrossRef]

186. Yun, J.; Puri, R.; Yang, H.; Lizzio, M.A.; Wu, C.; Sheng, Z.-H.; Guo, M. MUL1 acts in parallel to the PINK1/parkin pathway in regulating mitofusin and compensates for loss of PINK1/parkin. eLife 2014, 3, e01958. [CrossRef] [PubMed]

187. Szargel, R.; Shani, V.; Abd Elghani, F.; Mekies, L.N.; Liani, E.; Rott, R.; Engelender, S. The PINK1, synphilin-1 and SIAH-1 complex constitutes a novel mitophagy pathway. Hum. Mol. Genet. 2016, 25, 3476-3490. [CrossRef] [PubMed]

188. Villa, E.; Proïcs, E.; Rubio-Patiño, C.; Obba, S.; Zunino, B.; Bossowski, J.P.; Rozier, R.M.; Chiche, J.; Mondragón, L.; Riley, J.S.; et al Parkin-Independent Mitophagy Controls Chemotherapeutic Response in Cancer Cells. Cell Rep. 2017, 20, 2846-2859. [CrossRef]

189. Zachari, M.; Gudmundsson, S.R.; Li, Z.; Manifava, M.; Cugliandolo, F.; Shah, R.; Smith, M.; Stronge, J.; Karanasios, E.; Piunti, C.; et al. Selective Autophagy of Mitochondria on a Ubiquitin-Endoplasmic-Reticulum Platform. Dev. Cell 2019, 50, 627-643.e5. [CrossRef]

190. Lazarou, M.; Sliter, D.A.; Kane, L.A.; Sarraf, S.A.; Wang, C.; Burman, J.L.; Sideris, D.P.; Fogel, A.I.; Youle, R.J. The ubiquitin kinase PINK1 recruits autophagy receptors to induce mitophagy. Nature 2015, 524, 309-314. [CrossRef]

191. Heo, J.-M.; Ordureau, A.; Paulo, J.A.; Rinehart, J.; Harper, J.W. The PINK1-PARKIN Mitochondrial Ubiquitylation Pathway Drives a Program of OPTN/NDP52 Recruitment and TBK1 Activation to Promote Mitophagy. Mol. Cell 2015, 60, 7-20. [CrossRef]

192. Richter, B.; Sliter, D.A.; Herhaus, L.; Stolz, A.; Wang, C.; Beli, P.; Zaffagnini, G.; Wild, P.; Martens, S.; Wagner, S.A.; et al Phosphorylation of OPTN by TBK1 enhances its binding to Ub chains and promotes selective autophagy of damaged mitochondria. Proc. Natl. Acad. Sci. USA 2016, 113, 4039-4044. [CrossRef]

193. Wild, P.; Farhan, H.; McEwan, D.G.; Wagner, S.; Rogov, V.V.; Brady, N.R.; Richter, B.; Korac, J.; Waidmann, O.; Choudhary, C.; et al. Phosphorylation of the Autophagy Receptor Optineurin Restricts Salmonella Growth. Science 2011, 333, 228-233. [CrossRef] [PubMed]

194. Itakura, E.; Kishi-Itakura, C.; Koyama-Honda, I.; Mizushima, N. Structures containing Atg9A and the ULK1 complex independently target depolarized mitochondria at initial stages of Parkin-mediated mitophagy. J. Cell Sci. 2012, 125, 1488-1499. [CrossRef] [PubMed]

195. Karanasios, E.; Walker, S.A.; Okkenhaug, H.; Manifava, M.; Hummel, E.; Zimmermann, H.; Ahmed, Q.; Domart, M.-C.; Collinson, L.; Ktistakis, N.T. Autophagy initiation by ULK complex assembly on ER tubulovesicular regions marked by ATG9 vesicles. Nat. Commun. 2016, 7, 12420. [CrossRef]

196. Axe, E.L.; Walker, S.A.; Manifava, M.; Chandra, P.; Roderick, H.L.; Habermann, A.; Griffiths, G.; Ktistakis, N.T. Autophagosome formation from membrane compartments enriched in phosphatidylinositol 3-phosphate and dynamically connected to the endoplasmic reticulum. J. Cell Biol. 2008, 182, 685-701. [CrossRef] [PubMed]

197. Burman, C.; Ktistakis, N.T. Regulation of autophagy by phosphatidylinositol 3-phosphate. FEBS Lett. 2010, 584, 1302-1312. [CrossRef] [PubMed]

198. Nanao, T.; Koike, M.; Yamaguchi, J.; Sasaki, M.; Uchiyama, Y. Cellular localization and tissue distribution of endogenous DFCP1 protein. Biomed. Res. 2015, 36, 121-133. [CrossRef] [PubMed]

199. Polson, H.E.J.; de Lartigue, J.; Rigden, D.J.; Reedijk, M.; Urbé, S.; Clague, M.J.; Tooze, S.A. Mammalian Atg18 (WIPI2) localizes to omegasome-anchored phagophores and positively regulates LC3 lipidation. Autophagy 2010, 6, 506-522. [CrossRef]

200. Dooley, H.C.; Razi, M.; Polson, H.E.J.; Girardin, S.E.; Wilson, M.I.; Tooze, S.A. WIPI2 Links LC3 Conjugation with PI3P, Autophagosome Formation, and Pathogen Clearance by Recruiting Atg12-5-16L1. Mol. Cell 2014, 55, 238-252. [CrossRef]

201. Kabeya, Y.; Mizushima, N.; Yamamoto, A.; Oshitani-Okamoto, S.; Ohsumi, Y.; Yoshimori, T. LC3, GABARAP and GATE16 localize to autophagosomal membrane depending on form-II formation. J. Cell Sci. 2004, 117, 2805-2812. [CrossRef]

202. Zhen, Y.; Spangenberg, H.; Munson, M.J.; Brech, A.; Schink, K.O.; Tan, K.-W.; Sørensen, V.; Wenzel, E.M.; Radulovic, M.; Engedal, N.; et al. ESCRT-mediated phagophore sealing during mitophagy. Autophagy 2020, 16, 826-841. [CrossRef] [PubMed]

203. Kim, J.; Kundu, M.; Viollet, B.; Guan, K.-L. AMPK and mTOR regulate autophagy through direct phosphorylation of Ulk1. Nat. Cell Biol. 2011, 13, 132-141. [CrossRef] [PubMed]

204. Puente, C.; Hendrickson, R.C.; Jiang, X. Nutrient-regulated Phosphorylation of ATG13 Inhibits Starvation-induced Autophagy. J. Biol. Chem. 2016, 291, 6026-6035. [CrossRef] [PubMed]

205. Kim, S.G.; Hoffman, G.R.; Poulogiannis, G.; Buel, G.R.; Jang, Y.J.; Lee, K.W.; Kim, B.-Y.; Erikson, R.L.; Cantley, L.C.; Choo, A.Y.; et al. Metabolic Stress Controls mTORC1 Lysosomal Localization and Dimerization by Regulating the TTT-RUVBL1/2 Complex Mol. Cell 2013, 49, 172-185. [CrossRef] [PubMed]

206. Bartolomé, A.; García-Aguilar, A.; Asahara, S.-I.; Kido, Y.; Guillén, C.; Pajvani, U.B.; Benito, M. MTORC1 Regulates both General Autophagy and Mitophagy Induction after Oxidative Phosphorylation Uncoupling. Mol. Cell Biol. 2017, 37, e00441-17. [CrossRef] 
207. Bartolome, A.; Kimura-Koyanagi, M.; Asahara, S.-I.; Guillen, C.; Inoue, H.; Teruyama, K.; Shimizu, S.; Kanno, A.; Garcia-Aguilar, A.; Koike, M.; et al. Pancreatic -Cell Failure Mediated by mTORC1 Hyperactivity and Autophagic Impairment. Diabetes 2014, 63, 2996-3008. [CrossRef]

208. Bordi, M.; Darji, S.; Sato, Y.; Mellén, M.; Berg, M.J.; Kumar, A.; Jiang, Y.; Nixon, R.A. mTOR hyperactivation in Down Syndrome underlies deficits in autophagy induction, autophagosome formation, and mitophagy. Cell Death Dis. 2019, 10, 563. [CrossRef]

209. Vadysirisack, D.D.; Ellisen, L.W. MTOR Activity Under Hypoxia. In mTOR; Methods in Molecular Biology; Humana Press: New York, NY, USA, 2012; pp. 45-58.

210. Dou, Q.; Chen, H.-N.; Wang, K.; Yuan, K.; Lei, Y.; Li, K.; Lan, J.; Chen, Y.; Huang, Z.; Xie, N.; et al. Ivermectin Induces Cytostatic Autophagy by Blocking the PAK1/Akt Axis in Breast Cancer. Cancer Res. 2016, 76, 4457-4469. [CrossRef]

211. Hirota, Y.; Yamashita, S.; Kurihara, Y.; Jin, X.; Aihara, M.; Saigusa, T.; Kang, D.; Kanki, T. Mitophagy is primarily due to alternative autophagy and requires the MAPK1 and MAPK14 signaling pathways. Autophagy 2015, 11, 332-343. [CrossRef]

212. Nguyen, T.N.; Padman, B.S.; Lazarou, M. Deciphering the Molecular Signals of PINK1/Parkin Mitophagy. Trends Cell Biol. 2016, 26, 733-744. [CrossRef]

213. Padman, B.S.; Nguyen, T.N.; Uoselis, L.; Skulsuppaisarn, M.; Nguyen, L.K.; Lazarou, M. LC3/GABARAPs drive ubiquitinindependent recruitment of Optineurin and NDP52 to amplify mitophagy. Nat. Commun. 2019, 10, 408. [CrossRef] [PubMed]

214. Yamano, K.; Wang, C.; Sarraf, S.A.; Münch, C.; Kikuchi, R.; Noda, N.N.; Hizukuri, Y.; Kanemaki, M.T.; Harper, W.; Tanaka, K.; et al. Endosomal Rab cycles regulate Parkin-mediated mitophagy. eLife 2018, 7, e31326. [CrossRef] [PubMed]

215. Yamano, K.; Fogel, A.I.; Wang, C.; van der Bliek, A.M.; Youle, R.J. Mitochondrial Rab GAPs govern autophagosome biogenesis during mitophagy. eLife 2014, 3, e01612. [CrossRef] [PubMed]

216. Jimenez-Orgaz, A.; Kvainickas, A.; Nägele, H.; Denner, J.; Eimer, S.; Dengjel, J.; Steinberg, F. Control of RAB7 activity and localization through the retromer-TBC1D5 complex enables RAB7-dependent mitophagy. EMBO J. 2018, 37, 235-254. [CrossRef] [PubMed]

217. Heo, J.-M.; Ordureau, A.; Swarup, S.; Paulo, J.A.; Shen, K.; Sabatini, D.M.; Harper, J.W. RAB7A phosphorylation by TBK1 promotes mitophagy via the PINK-PARKIN pathway. Sci. Adv. 2018, 4, eaav0443. [CrossRef]

218. Tsuboyama, K.; Koyama-Honda, I.; Sakamaki, Y.; Koike, M.; Morishita, H.; Mizushima, N. The ATG conjugation systems are important for degradation of the inner autophagosomal membrane. Science 2016, 354, 1036-1041. [CrossRef]

219. Lee, J.W.; Park, S.; Takahashi, Y.; Wang, H.-G. The Association of AMPK with ULK1 Regulates Autophagy. PLoS ONE 2010, 5 , e15394. [CrossRef]

220. Egan, D.F.; Shackelford, D.B.; Mihaylova, M.M.; Gelino, S.; Kohnz, R.A.; Mair, W.; Vasquez, D.S.; Joshi, A.; Gwinn, D.M.; Taylor, R.; et al. Phosphorylation of ULK1 (hATG1) by AMP-Activated Protein Kinase Connects Energy Sensing to Mitophagy. Science 2011, 331, 456-461. [CrossRef]

221. Shang, L.; Chen, S.; Du, F.; Li, S.; Zhao, L.; Wang, X. Nutrient starvation elicits an acute autophagic response mediated by Ulk1 dephosphorylation and its subsequent dissociation from AMPK. Proc. Natl. Acad. Sci. USA 2011, 108, 4788-4793. [CrossRef]

222. Hoffman, N.J.; Parker, B.L.; Chaudhuri, R.; Fisher-Wellman, K.H.; Kleinert, M.; Humphrey, S.J.; Yang, P.; Holliday, M.; Trefely, S.; Fazakerley, D.J.; et al. Global Phosphoproteomic Analysis of Human Skeletal Muscle Reveals a Network of Exercise-Regulated Kinases and AMPK Substrates. Cell Metab. 2015, 22, 922-935. [CrossRef]

223. Gan, W.; Zhang, C.; Siu, K.Y.; Satoh, A.; Tanner, J.A.; Yu, S. ULK1 phosphorylates Sec23A and mediates autophagy-induced inhibition of ER-to-Golgi traffic. BMC Cell Biol. 2017, 18, 22. [CrossRef] [PubMed]

224. Alsaadi, R.M.; Losier, T.T.; Tian, W.; Jackson, A.; Guo, Z.; Rubinsztein, D.C.; Russell, R.C. ULK1-mediated phosphorylation of ATG16L1 promotes xenophagy, but destabilizes the ATG16L1 Crohn's mutant. EMBO Rep. 2019, 20, e46885. [CrossRef]

225. Rajesh, S.; Bago, R.; Odintsova, E.; Muratov, G.; Baldwin, G.; Sridhar, P.; Rajesh, S.; Overduin, M.; Berditchevski, F. Binding to Syntenin-1 Protein Defines a New Mode of Ubiquitin-based Interactions Regulated by Phosphorylation. J. Biol. Chem. 2011, 286, 39606-39614. [CrossRef] [PubMed]

226. Takaesu, G.; Kobayashi, T.; Yoshimura, A. TGF -activated kinase 1 (TAK1)-binding proteins (TAB) 2 and 3 negatively regulate autophagy. J. Biochem. 2012, 151, 157-166. [CrossRef]

227. Dunlop, E.A.; Hunt, D.K.; Acosta-Jaquez, H.A.; Fingar, D.C.; Tee, A.R. ULK1 inhibits mTORC1 signaling, promotes multisite Raptor phosphorylation and hinders substrate binding. Autophagy 2011, 7, 737-747. [CrossRef]

228. Löffler, A.S.; Alers, S.; Dieterle, A.M.; Keppeler, H.; Franz-Wachtel, M.; Kundu, M.; Campbell, D.G.; Wesselborg, S.; Alessi, D.R.; Stork, B. Ulk1-mediated phosphorylation of AMPK constitutes a negative regulatory feedback loop. Autophagy 2011, 7, 696-706. [CrossRef] [PubMed]

229. Russell, R.C.; Tian, Y.; Yuan, H.; Park, H.W.; Chang, Y.-Y.; Kim, J.; Kim, H.; Neufeld, T.P.; Dillin, A.; Guan, K.-L. ULK1 induces autophagy by phosphorylating Beclin-1 and activating VPS34 lipid kinase. Nat. Cell Biol. 2013, 15, 741-750. [CrossRef]

230. Egan, D.F.; Chun, M.G.H.; Vamos, M.; Zou, H.; Rong, J.; Miller, C.J.; Lou, H.J.; Raveendra-Panickar, D.; Yang, C.-C.; Sheffler, D.J.; et al. Small Molecule Inhibition of the Autophagy Kinase ULK1 and Identification of ULK1 Substrates. Mol. Cell 2015, 59, 285-297. [CrossRef]

231. Park, J.-M.; Jung, C.H.; Seo, M.; Otto, N.M.; Grunwald, D.; Kim, K.H.; Moriarity, B.; Kim, Y.-M.; Starker, C.; Nho, R.S.; et al. The ULK1 complex mediates MTORC1 signaling to the autophagy initiation machinery via binding and phosphorylating ATG14. Autophagy 2016, 12, 547-564. [CrossRef] 
232. Joo, J.H.; Wang, B.; Frankel, E.; Ge, L.; Xu, L.; Iyengar, R.; Li-Harms, X.; Wright, C.; Shaw, T.I.; Lindsten, T.; et al. The Noncanonical Role of ULK/ATG1 in ER-to-Golgi Trafficking Is Essential for Cellular Homeostasis. Mol. Cell 2016, 62, 491-506. [CrossRef]

233. Liang, J.; Xu, Z.-X.; Ding, Z.; Lu, Y.; Yu, Q.; Werle, K.D.; Zhou, G.; Park, Y.-Y.; Peng, G.; Gambello, M.J.; et al. Myristoylation confers noncanonical AMPK functions in autophagy selectivity and mitochondrial surveillance. Nat. Commun. 2015, 6, 7926. [CrossRef]

234. Tian, W.; Li, W.; Chen, Y.; Yan, Z.; Huang, X.; Zhuang, H.; Zhong, W.; Chen, Y.; Wu, W.; Lin, C.; et al. Phosphorylation of ULK1 by AMPK regulates translocation of ULK1 to mitochondria and mitophagy. FEBS Lett. 2015, 589, 1847-1854. [CrossRef]

235. Kundu, M.; Lindsten, T.; Yang, C.-Y.; Wu, J.; Zhao, F.; Zhang, J.; Selak, M.A.; Ney, P.A.; Thompson, C.B. Ulk1 plays a critical role in the autophagic clearance of mitochondria and ribosomes during reticulocyte maturation. Blood 2008, 112, 1493-1502. [CrossRef]

236. Honda, S.; Arakawa, S.; Nishida, Y.; Yamaguchi, H.; Ishii, E.; Shimizu, S. Ulk1-mediated Atg5-independent macroautophagy mediates elimination of mitochondria from embryonic reticulocytes. Nat. Commun. 2014, 5, 4004. [CrossRef] [PubMed]

237. Laker, R.C.; Drake, J.C.; Wilson, R.J.; Lira, V.A.; Lewellen, B.M.; Ryall, K.A.; Fisher, C.C.; Zhang, M.; Saucerman, J.J.; Goodyear, L.J.; et al. Ampk phosphorylation of Ulk1 is required for targeting of mitochondria to lysosomes in exercise-induced mitophagy. Nat. Commun. 2017, 8, 548. [CrossRef]

238. Hung, C.-M.; Lombardo, P.S.; Malik, N.; Brun, S.N.; Hellberg, K.; Van Nostrand, J.L.; Garcia, D.; Baumgart, J.; Diffenderfer, K.; Asara, J.M.; et al. AMPK/ULK1-mediated phosphorylation of Parkin ACT domain mediates an early step in mitophagy. Sci. Adv. 2021, 7, eabg4544. [CrossRef] [PubMed]

239. Seabright, A.P.; Fine, N.H.F.; Barlow, J.P.; Lord, S.O.; Musa, I.; Gray, A.; Bryant, J.A.; Banzhaf, M.; Lavery, G.G.; Hardie, D.G.; et al. AMPK activation induces mitophagy and promotes mitochondrial fission while activating TBK1 in a PINK1-Parkin independent manner. FASEB J. 2020, 34, 6284-6301. [CrossRef] [PubMed]

240. Seabright, A.P.; Lai, Y.-C. Regulatory Roles of PINK1-Parkin and AMPK in Ubiquitin-Dependent Skeletal Muscle Mitophagy. Front. Physiol. 2020, 11, 608474. [CrossRef]

241. Drake, J.C.; Wilson, R.J.; Laker, R.C.; Guan, Y.; Spaulding, H.R.; Nichenko, A.S.; Shen, W.; Shang, H.; Dorn, M.V.; Huang, K.; et al. Mitochondria-localized AMPK responds to local energetics and contributes to exercise and energetic stress-induced mitophagy. Proc. Natl. Acad. Sci. USA 2021, 118, e2025932118. [CrossRef]

242. Huttlin, E.L.; Jedrychowski, M.P.; Elias, J.E.; Goswami, T.; Rad, R.; Beausoleil, S.A.; Villén, J.; Haas, W.; Sowa, M.E.; Gygi, S.P. A Tissue-Specific Atlas of Mouse Protein Phosphorylation and Expression. Cell 2010, 143, 1174-1189. [CrossRef]

243. Wang, B.; Nie, J.; Wu, L.; Hu, Y.; Wen, Z.; Dong, L.; Zou, M.-H.; Chen, C.; Wang, D.W. AMPK $\alpha 2$ Protects Against the Development of Heart Failure by Enhancing Mitophagy via PINK1 Phosphorylation. Circ. Res. 2018, 122, 712-729. [CrossRef] [PubMed]

244. Lee, S.B.; Kim, J.J.; Han, S.-A.; Fan, Y.; Guo, L.-S.; Aziz, K.; Nowsheen, S.; Kim, S.S.; Park, S.-Y.; Luo, Q.; et al. The AMPK-Parkin axis negatively regulates necroptosis and tumorigenesis by inhibiting the necrosome. Nat. Cell Biol. 2019, 21, 940-951. [CrossRef]

245. Pei, S.; Minhajuddin, M.; Adane, B.; Khan, N.; Stevens, B.M.; Mack, S.C.; Lai, S.; Rich, J.N.; Inguva, A.; Shannon, K.M.; et al AMPK/FIS1-Mediated Mitophagy Is Required for Self-Renewal of Human AML Stem Cells. Cell Stem Cell 2018, 23, 86-100.e6. [CrossRef] [PubMed]

246. Lu, X.; Xuan, W.; Li, J.; Yao, H.; Huang, C.; Li, J. AMPK protects against alcohol-induced liver injury through UQCRC2 to up-regulate mitophagy. Autophagy 2021, 17, 3622-3643. [CrossRef] [PubMed]

247. Jang, J.E.; Eom, J.-I.; Jeung, H.-K.; Cheong, J.-W.; Lee, J.Y.; Kim, J.S.; Min, Y.H. Targeting AMPK-ULK1-mediated autophagy for combating BET inhibitor resistance in acute myeloid leukemia stem cells. Autophagy 2017, 13, 761-762. [CrossRef] [PubMed]

248. Toyama, E.Q.; Herzig, S.; Courchet, J.; Lewis, T.L.; Losón, O.C.; Hellberg, K.; Young, N.P.; Chen, H.; Polleux, F.; Chan, D.C.; et al. AMP-activated protein kinase mediates mitochondrial fission in response to energy stress. Science 2016, 351, 275-281. [CrossRef]

249. Zong, Y.; Zhang, C.-S.; Li, M.; Wang, W.; Wang, Z.; Hawley, S.A.; Ma, T.; Feng, J.-W.; Tian, X.; Qi, Q.; et al. Hierarchical activation of compartmentalized pools of AMPK depends on severity of nutrient or energy stress. Cell Res. 2019, 29, 460-473. [CrossRef] 